\title{
Biosensors for Cancer Biomarkers
}

\author{
Zihni Onur Uygun ${ }^{1}$ and Mustafa Kemal Sezgintürk ${ }^{2}$ \\ ${ }^{1}$ Çanakkale Onsekiz Mart University \\ ${ }^{2}$ Namık Kemal University, \\ Turkey
}

\section{Introduction}

The cancer is experessed as a disorder of chaos which cause an impairment of biochemical pathways in living metabolisms. In particular, mulfunctioning of the controls of cells throught the human body is mostly observed breakdown in cancer. Actually, this is not single way to form cancer such that there are many chance to initiate cancer in the body. We know that most of our cells carry their own genetic materials which give them an opportunity to multiply once more. And this condition describes why the proliferation of uncontrolled cells in countless parts of the body is extremely important. In fact, a terrible cell turnover involving death and replacement of cell, consists everlastingly in many tissues in human body.The presantation, development, and outcome of the cancer are extremely different and complex from one patient to other. Moreover the cellular and molecular levels of the cancer show the similar heterogenity and uncertainty. During cancer process cells undergo serious metabolic changes which give rise to proliferate in an excessive and untimely way. Also these changes allow to cancer cells escape surveillance by immune system (Merlo et al., 2006). Mutations originate in the DNA sequences should initiate cancer (Herceg and Hainaut, 2007). A single base change results in a changing aminoacid to be integrated into a protein synthesized. This is enough to extremely change the three dimensional structure of that protein. Besides the activity of the protein will change dramatically. A large number of bases can be converted by other DNA differentiations. This will lead to synthesis of abnormal proteins. Significantly, these alterations can be monitored by sequencing the DNA of the cell and used to detect of cancer.

\section{Cancer biomarkers}

There is no standard definition for "biomarker" that is universally used. In 1999, the US National Institutes of Health/Food and Drug Administration Working Group drafted a definition of a biomarker as a characteristic that is objectively measured and evaluated as an indicator of normal biological processes, pathogenic processes or pharmacological response to a therapeutic intervention. Biomarkers could be found in body and they are quantifiable molecules such as proteins, metabolites, DNA, or RNA. The abnormal concentrations of such biomarkers are indicator for a pathological condition in body, such as cancer. A biomarker also could be a molecule occured as a specific response of the metabolism to the presence of cancer. Every type of cancer could be associated with gene modifications and alterations in protein function. These gene modifications and protein changes can be useful 
indicators of any cancer types. Besides they could be used to idetify prognosis, progression and therapeutic response of the disease(Sriwastava, 2007). For development, evaluating, and validating biomarkers guding principles known as the five-phase approach has been established by the US National Cancer Institute's Early Detection Network (http://www.cancer.gov/edrn). The guidelines are very important for the usage of biomarkers in clinical applications. The five phases mentioned above ensure the principles and study design foundations for validating biomarkers for clinical use in early diagnosis of cancer. Phase 1 is the discovery pahse. Phase 2 is the validation phase in which the biomarkers are verified to determine their capacity for distinguishing between people with cancer and those without. In Phase 3, the capacity of a biomarker to detect preclinical disease is investigated. Phase 4 comprehends screening tests. And the last phase 5 , focuses on the large-scale population experiments that appreciate the role of the biomarker for detection of cancer (Pepe et al., 2001).

\section{Transducers used for detection of cancer biomarkers}

Early diagnosis of cancer plays a major role for treatment(Yuan et al., 2001; Faraggi and Kramar, 2000; Zhang et al., 2007; Wu et al., 2007). The analytical techniques which are improved for detection of biomarkers are based on highly specific molecular recognition between antibody and antigen to form immunocomplex (Andrey et al..1998). In Addition these analytical methods are used for clinical researches(Itoh and Ichhara,2001; Trull 2001; Worwood, 2002) and biochemical analysis (Panteghini, 2000; Rossier et al., 2002; Sato et al., 2003). Because of highly specific molecular recognition characteristics of antigen and antibody, immunosensors are based on the interaction between antigen and antibody which are widely used for quantitative detection of biomarkers(Liu and Ju, 2005; Huang et al., 2010; Rusling et al., 2009; Tang et al., 2008a). Transducers are devices that are employed for preparation of immuosensors and transform the biomolecular recognition signals into electrical signals. Transducers can be divided into three main groups due to their sensing signal type; electrochemical, optic, and piezoelectric (Tothill, Turner, 2003). Choosing the exact transducer depends on a biomarker which is investigated and a signal which is occurred by biomarker reaction. It is very important to choose the correct transducer in routine utilization, for this reason the measurement principle of transducers are supposed to be proper for fabrication and commercial usage. Recently necessity of this kind of practical and economic devices by the public makes biosensors more important and attractive. Therefore the utilizing of biosensors for development of clinical researches and self-using by patients increase all over the world.

In this section; it is discussed that biosensor systems which are developed for the detection of biomarkers. The discussion will be focuses on the types of transducers used in the biosensor systems. First; brief information about cancer biomarkers which are diagnosed by the biosensor developed will be given, and after that the biosensor systems, that are developed for the detection any cancer marker, are discussed deeply.

\subsection{Electrochemical transducers}

Electrochemical biosensors are used in point-of-care devices since they were portable, simple, easy to use, cost effective and in most cases disposable. The electrochemical instruments used with the biosensors have been miniaturised to small pocket size devices which make them applicable for home use or the doctor's surgery (Tothill, 2009). As a result 
of antigen antibody interaction forms electroanalytical signals. Immunosensors based on measurement of these signals are widely used for clinical applications(Liu et al., 2001; S'anchez and Garc'1a, 1999; Dai et al., 2003; Andrey et al., 1998). Electrochemical transducers divided into four groups due to their sensing signal type; amperometric, potansiometric, conductometric and impedimetric.(Liu et al., 2001; Zhang et al., 2004; Hianik et al., 1999; Ruan et al., 2002). However sensing the signals, which are formed by bioaffinity interactions, is possible to detect in narrow electrochemical techniques. Below of this passage, electrochemical biosensors those are developed for cancer biomerkers as now, are discussed.

\subsubsection{Electrochemical immunosensors developed for detection of Alfa-Fetoprotein}

Alfa-fetoprotein(AFP) is a normal serum protein that is synthesized by liver, yolk sac and gastrointestinal tract. AFP, a glycoprotein, is about $70 \mathrm{kDa}$ weight and AFP contains an asparagines coupling residue. This biomarker levels are about $3 \mathrm{mg} / \mathrm{mL}$ when pregnancy occurs then decreases dramatically after birth and reaches $10 \mathrm{ng} / \mathrm{mL}$. When overexpression occurs by AFP synthesizing tissues that indicates liver cancer. In addition to this situation points out an evidence of the risk of gamet cell cancer \%75-80 positively(Bisceglie et al., 2005; Yuen and Lai, 2005; Zinkin et al. 2008). Consequently the detection of AFP levels in lower levels is very important.

J.-H. Maeng et al. developed a novel microfluidic immunosensor system which measured AFP levels. In this system, a PDMS-glass microbiochip was used, this microbiochip can detect AFP antigen antibody interactions by using electrical signals. There were platinum electrodes to gain electrical signals, a microchannel and pillar-type microfilter to blockade sample flow. These microbeads, microfilters and immune-gold silver coated complexes(IGSS) were used to amplify the response signal(Baschong and Stierhof, 1998; Lackie, 1996; Weipoltshammer et al., 2000); thus more sensitive signals obtain. For the detection AFP levels; microbeads were conjugated with streptavidine, antibodies were conjugated with biotins. AFP was added on these conjugates and AuNPs were conjugated with these conjugates on microchannels. After these experiment steps, secondary antibody was added on these conjugates. Eventually a silver enchancer solution was flowed to the system to amplify electrical signal. A microfilter was deployed on this PDMS-glass hybrid immunoassay microchip adjacent to platinum electrode. Therefore; firstly streptavidinbiotin-AFP-Ab $b_{2}$ conjugates injected into the PDMS-glass hybrid microchip, secondly this conjugate move to the filters, the filters hold the conjugate solution and a bulk of conjugates formed on the Platinum electrode. Consequently, not only grater mass of bulk obtains and amplify signal, but also silver enchancer coated more conjugates and increased the conductivity and sensitivity. In addition simple to modify, high reaction efficiency and both molecular and cellular level analysis potantials make this immunosensor individual AFP sensing system(Bienvenue et al., 2006; Choi et al., 2002; Lim and Zhang, 2007; Sato et al., 2002). A schematic representation of the biosensor is given in figure 1.

The effect of incubation time and flow rate of conjugate solution are effective parameters for working of this immunosensor. The important points; minimum incubation time and antigen binding time are individual parts of this system. Nanoparticles, which are used for coating, have a nucleation sites that catalyze silver ion reduction(Liang et al., 2004; Su et al., 2001; Xue et al., 2002), therefore this effect of reduction leads to elevated background signal which hides results and microbeads are coated silver enchancer to ignore self-nucleation. Because of using silver enchancer decreases the system's conductivity between 1-10 k $\Omega$ 


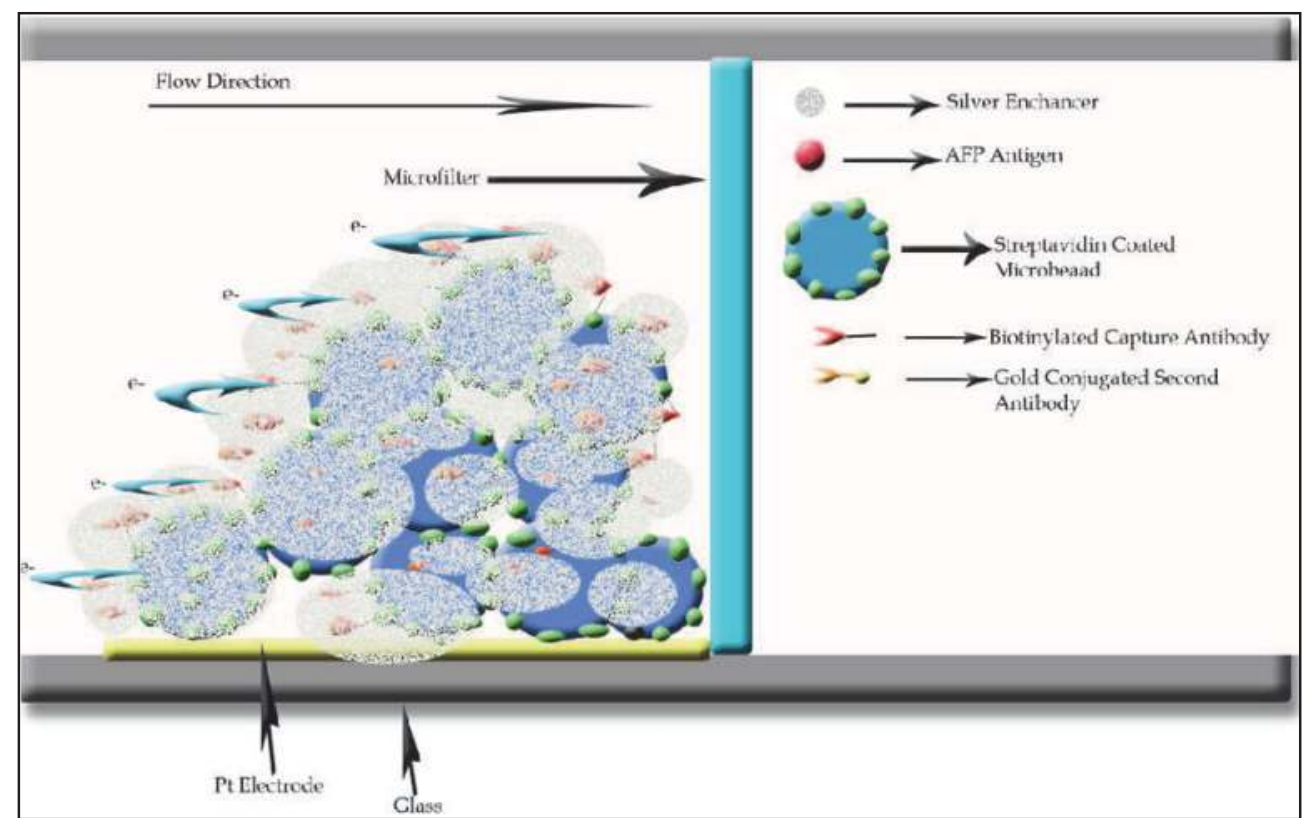

Fig. 1. A schematic representation of AFP sensing by a microfluidic immunosensor system

furthermore doesn't allow to form non-spesific binding, hence the system doesn't need any pretreatment for measurement. Preparation of the immunosensor, incubation time and measurement time totally took less than 1 hour. Minimum detection limit of AFP is $1-10^{3}$ $\mathrm{ng} / \mathrm{mL}$ and the correlation coefficient is 0.9746 .

Wei et al. aimed to develop a label free detection of an immunsensor. Graphene and thionin nanocomposit film were employed on immunosensor. Recently graphene sheets that consist of single carbon atoms in hexagonal shape, are single layer phenomenon(Kauffmann, 2007). Graphene sheets show stability and resistant to higher electrical potentials, due to these properties they are in use for biosensor technologies(Wu et al.,2010; Lin et al., 2009; Liu et al. 2010; Shan et al. 2010; Wang et al. 2009; Babya et al. 2010). Because of nanomaterials's high surface/volume ratio, nanomaterials provide high molecular loading surface. Furthermore these properties amplify electroactivity of thionin. This composition which is located on biosensor increases sensitivity. Graphene sheets were prepared according to Hummer method(Liu et al. 2008) graphene oxide was reduced a method improved by Y. Wang et al. (Y. Wang et al. 2009). Antibodies were immobilized on graphene sheets by a cross-linker agent glutaraldehyde. For prevention of non-spesific boundings, BSA was used to block the reactive aldehyde groups. AFP linear detection limit was between 0.05 and $2 \mathrm{ng} / \mathrm{mL}$. The low detection limit was obtained $5.77 \mathrm{pg} / \mathrm{mL}(\mathrm{S} / \mathrm{N}=3)$. According to Wei et al. there were two factor that provided very low detection limit, firstly; because of high surface area of graphene adsorbed high number of $\mathrm{TH}$ and increased antibody conjugation, secondly; conjugation of GS-TH thin film layer increased electroactivity for detection low concentration limits. Three electrode system was used for this experiment. This immunosensor more sensitive than other systems which are employed nanomaterials(Su, 2009 et al.; Sun et al., 2009; Wang, 2009 ). As it known that reproductivity is one of important 
characteristics of an ideal biosensor. For the detection of $1 \mathrm{ng} / \mathrm{mL}$ AFP, the relative standart deviation of measurements for five prepared electrode was $5.0 \%$ in which suggested precision and reproducibility of immunosensor was quite good. For the selectivity tests IgG, Vit. C, glucose and BSA were used and electrode respond was less than 5\%, consequently selectivity of this biosensor was quite good. The stability test of this biosensor was stored 3 weeks and the RSD result was $4.9 \%$. The advantageous of the biosensor were simple to prepare, label free and practical measurement system.

Tang et al. was developed another AFP detection immunosensor system which was based on conductometric and was employed carbon nanoparticles as label. The most important advantages of conductometric immunosensors are low prices, high sensitivity and low energy consumption in compliance with the micro system is perfect. Therefore; the novel biosensor designs often come from among the preferred methods(Hnaiein et al., 2008). Conductometric enzyme immunoassay principle of measurement systems, based on conductometric changing that results from a reaction occurs between two electrodes(Watson et al. 1987). According to the measurement system, most of antigen-antibody interactions are not able to occur any electrochemical signal. Thus the characteristics of electrochemical signaling enzymes (HRP, ALP, etc.) used for labeling the production of the signal obtaining to increase the low signal. In this manner; the technique could be used for development of many different measurement techniques. However some antibodies are limited to carry an enzyme. To solve this problem nanomaterials are combined with bioanalytical systems which decrease these limitations(Hiep et al,, 2010; MinhHiep et al.,2010; Yoo et al.,2010 ). Because of carbon nanoparticles used in this study (CNPS), the remarkable properties of amorphous $\mathrm{sp}^{2}-\Pi$ electrons is quite noteworthy(Dumitrescu et al., 2009). In this study, CNPHRP-anti-AFP, sandwiches were prepared on the basis of the method and conductometric determination of AFP was carried out as measurement system. Developed by the physical properties of nanoparticles used in this method can connect a maximum level of biomolecules with a created micro environment. Measurement of HRP to determine the concentration of iodine from the environment as a result of conversion is based on peroxide. According to electrochemical measurements carried out in a rapid increase in the reduction and oxidation current was observed that a sharp decline. According to Tang et al. the CNPHRP-anti-AFP conductometric signal is higher than the building of the reasons for conjugation; CNPS high surface area / volume ratio due to the creation of further conjugation with HRP, HRP-anti-AFP according to this ratio is less than just a result of the addition of AFP (not clear what is required), as has been reported. This optimization stages of the conductometric response of the system was prepared by increasing the electrodeposition time decreased. Linear range of the method is 0.1 to $500 \mathrm{ng} / \mathrm{mL}$, as determined and Immunosensors $50 \mathrm{pg} / \mathrm{mL}$, has a lower limit of determination. A summarize for AFP detection is given in Table 1 below.

\subsubsection{Electrochemical Immunosensors developed for detection of Annexin-II}

Lung cancer is a disease which is one of the worst ended cancer types. The symptoms of lung cancer and CT X-ray scattering of the disease with only four of process can be observed. The first stage of biomarker identification for diagnosis of lung cancer in recent years, based on the methods researched and began to develop rapidly (Heighway et al., 2002, Hirsch et al., 2001 and Qiao et al., 1997; Singhalet al., 2005; Belinsky, 2004). Annexin II, also known as Annexin encoded by the gene ANXA2 used in the diagnosis of lung 


\begin{tabular}{|c|c|c|c|c|}
\hline \multicolumn{4}{|c|}{ Table Of Electrochemical Transducers For Detection of AFP } \\
\hline $\begin{array}{c}\text { Measurement } \\
\text { Technique }\end{array}$ & $\begin{array}{c}\text { Immobilization } \\
\text { Technique }\end{array}$ & $\begin{array}{c}\text { Low Detection } \\
\text { Limit }\end{array}$ & $\begin{array}{c}\text { Lineer } \\
\text { Detection Limit }\end{array}$ & Reference \\
\hline Conductometric & $\begin{array}{c}\text { Microfluidic } \\
\text { immunosensor } \\
\text { system }\end{array}$ & $1 \mathrm{ng} / \mathrm{mL}$ & 1 to $10^{3} \mathrm{ng} / \mathrm{mL}$ & $\begin{array}{c}\text { Maeng et al., } \\
2008\end{array}$ \\
\hline Amperometric & $\begin{array}{c}\text { Graphene and } \\
\text { thionin nanocomposit } \\
\text { film }\end{array}$ & $5.77 \mathrm{pg} / \mathrm{mL}$ & 0.05 to $2 \mathrm{ng} / \mathrm{mL}$ & $\begin{array}{c}\text { Wei et al., } \\
2010\end{array}$ \\
\hline Conductometric & $\begin{array}{c}\text { CNP-HRP-anti-AFP, } \\
\text { sandwiches }\end{array}$ & $50 \mathrm{pg} / \mathrm{mL}$ & $\begin{array}{c}0.1 \text { to } 500 \\
\mathrm{ng} / \mathrm{mL}\end{array}$ & $\begin{array}{c}\text { Tang et al., } \\
2011\end{array}$ \\
\hline
\end{tabular}

Table 1. Electochemical Immunosensors for AFP detection

cancer(Takahashi et al., 1994). In terms of lung cancer, Annexin II what is a secreted protein, is not found in people with a solid, especially the stage of disease (Kim et al., 2007). In addition, the normal bronchial cells that secreted by intact lung bronchial epithelial cells can be used for the determination of the MUC5AC (Hovenverget al., 1996, Koo et al., 1999). Amperometric based electrochemical biosensors were developed for the early diagnosis of lung cancer biomarkers to determine the real-time mode (Wang et al., 1998; Darain et al., 2005; Shiddiky et al., 2007a, b). Biosensors allow to determine specific molecules. For this reason, recently nanomaterials such as CNTs QDS AuNPs can be used to improve the performance of biosensors. Nanomaterials, high surface area / volume ratio, high electrocatalytic activity and can easily be modified in a manner compatible with biomolecules are very useful in terms of their use in biosensor technology (Shiddiky et al., 2007a, b). Annexin II, as well as in electrochemical signal to give some of the biomarkers is not possible in theory, so biomarker is used for the determination of some special labeling.

D.-M, Kim et al. developed an immunosensor system for the analysis of MUC5A and AnnexinII for early diagnosis of lung cancer. This system is based on amperometric measurement using a label as a AnnexinII biomerker. The system consists of glucose oxidase as a label(Shankaran and Shim, 2002; Shiddiky et al., 2007b) have been appointed as amperometric. Glucose oxidase(Shankaran and Shim, 2002; Shiddiky et al., 2007b) was employed instead of the enzyme HRP to reduction of the glucose and was immobilized on surface the hydrazine was used to provide stabilization(Rahman et al., 2005). Immunosensor's measurement system is based on third-generation dendrimers immobilization with a covalent bond connection the foundation of hydrazine to polyclonal antibodies which are treated with AuNPs on the GCE (Rahman et al., 2005, Wang et al., 2007; Katz and Willner, 2004). The use of amine dendrimers increases the sensitivity of the system two or three times(Shiddiky et al., 2007b). First, gold nanoparticles were electrodepozited on the GCE, and then polymerized with TTCA by electropolymerization. Carboxyl groups on the poly-TTCA were activated with NHS and EDC(Shiddinky et al.) with amine groups on the poly-TTCA method of forming the amine groups are activated with glutaraldehyde for further bindings. After these ends are bond to the activated hydrazine sulfate. After measurement, the system is ready for the immobilization of antiAnnexin, Annexin II is required for the measurement of system pointing step of GOx, GOx solution of glutaraldehyde added to biomarker (Annexin II) activated on the connected 
ends, after this steps the active sides to block the amino acids lysine ( $\mathrm{pH}=7$ neutral) were used. The prepared immunosensor to verify the measurement controlled on biological fluids measurement should be made on the prepared normal bronchial cell cultures(Koo et al., 1999). Anti-Annexin II / Hyd / AuNP / Den / Polt-TTCA / AuNP-modified electrode in a solution of glucose measurement was carried out depending on the interaction of AnnexinGOx. The signal decreases the presence of free biomarker Annexin II, therefore, must be disposed of amperometric measurement of free as possible. This brought the measurement results have shown that 0.03 to $3 \mathrm{ng} / \mathrm{mL}$ Annexin II, the amount to be determined as linear. Dynamic range was measured in the 0.1 to $1 \mathrm{ng} / \mathrm{mL}$. R.S.D. $2.2 \%(\mathrm{n}=5)$ and measuring the amount of the minimum $0.051 \mathrm{ng} / \mathrm{ml}$, respectively. As we have seen extremely high sensitivity. Prepared bronchial cell cultures containing liquids examined of each species experiments of biomolecules to the response of immunosensor. Annexin II, a signal was not observed in normal cells, the addition of fluids with QCM measurements showed that the frequency change. The standard of the examination, with the added amount of Annexin II, $280 \pm 8 \mathrm{pg} / \mathrm{mL}$ was measured. As a result, D.-M, Kim et al. have developed a measurement system was extremely sensitive for early diagnosis of lung cancer. Sensitive measurement techniques such as QCM and impedance method with proven accuracy.

\subsubsection{Electrochemical immunosensors developed for the detection of CEA}

Carcinoembriyonic Antigen (CEA) is a biomarker occurring in cases of colon cancer, pancreatic cancer, uterine cancer and stomach cancer(Benchimol et al., 1989; Oikawa et al., 1989, Goldenberg et al., 1976). CEA is an acidic glycoprotein is approximately $200 \mathrm{kDa}$ molecular weight. Most of this glycoprotein synthesized during the formation of cancer(Benchimol et al., 1989; Schlageter et al., 1998). During the early diagnosis of cancer over-Express is vitally important. CEA is $<2.5 \mathrm{ng} / \mathrm{ml}$ for a non-smoker man, while nonsmokers $<5 \mathrm{ng} / \mathrm{mL}$ are around. In the presence of cancer is higher than 5 times this amount(Duffy, 2001).

W. Shi and Z. A reported a biosensor system based on electrostatic interaction for determination of CEA. The system shows good biocompatibility with immobilization materials have been chosen as, contains many amino group, a linear polysaccharide(Liu et al., 2010a, b) with negative charged groups on the chitosan(Liu et al., 2005) a good film layer observed due to form the nafion film. The main purpose of this system, a new membrane was prepared redox species is to adsorb on the film. Polietilendiamin were used to immobilization of antibody cross-linked on the electrode membrane and created with the electrolytic solution to facilitate the transfer of electrons between the AuNPs. Thus, antigen binding by blocking the electron transfer of redox-based measurement system's response was declined. (Liu and Gooding, 2009). AuNPs to be in $15 \mathrm{~nm}$ diameter(Yang et al. 2009) were prepared and were treated nafion to formed nafyon-AuNP complex. Ferrocene mixed with chitosan by sonication(Grabar et al. 1995). PEI treated with glutaraldehyde to modified electrode forming and the anti-CEA bound aldehyde ends. Nafyon-AuNP prevented leakage of ferrocene from system. With that of the secondary amine and negative charged Nafion and positively charged PEI to have facilitated the coexistence of two species via electrostatic interaction. A change in current density occurred after incubation with CEA. Stopping the transmission of electrical signals blocked electrostatic properties of electroactive layer of CEA. This was confirmed by a decrease in current. Prepared in conductivity compared to the control and AuNP-free sensor is determined to be less. In other words, the presence of AuNP increased the sensitivity of the system. Immunosensor 
offers 0.01 to $150 \mathrm{ng} / \mathrm{mL}$ linear measurement. For the control of the prepared AuNP-free sensor showed a narrower range of measurement 0.03 to $100 \mathrm{ng} / \mathrm{mL}$. RSD value of the sensor is $6 \%$. Because of these properties prepared by different techniques, a measurement technique that has proved to be more effective than most Immunosensors (Wu et al., 2006, Pan and Yang, 2007; Mauritz and Moore, 2004; Limbut et al., 2006, Tan et al., 2006; Tang and Rhine, 2008, Tang et al., 2008, Zhang et al., 2008, He et al., 2008, Zhang et al., 2007, Liu et al., 2010a, b, ; Thomson et al., 1969, Yang et al., 2010, Lin et al., 2004).

$\mathrm{X}$. Li et al. developed an immunosensor the poly-sulphanilic acid (PSAA) modified a glassy carbon electrode, due to the electrostatic interaction strategy. PSAA contains negative charge to interact the positively charged toluidine blue as a mediator and nano-Au as conductive agent facilitated binding of the anti-CEA in this system. HRP was used instead of BSA to prevent non-specific binding of the system. This is both non-specific bindings to blocked(Zhang et al., 2005; Zhuo et al., 2005, in press) and to use of TB as a mediator and $\mathrm{H}_{2} \mathrm{O}_{2}$ as a result of reduction feature makes the system more sensitive(Yang et al., 1998; Zhang et al., 2005). Radical cation method was used SAA to bond on GCE electrode(Cheng et al., 2001, Liu et al., 2000; Downard and Mohamed, 1999) to the PSAA / GCE modified electrode forming. Sulfonate groups of the modified electrode has been created with TB treatment. AuNP solution then immersed electrode to increase the surface area, this step was followed by immobilization with anti-CEA. Finally, the electrode immersed in HRP solution is ready for use as anti-CEA/HRP Immunosensors. All steps were followed by using the EIS. As is known, the electrode interface impedance spectroscopy is an effective method used in monitoring binding properties(Colvin et al., 1992, Gu et al., 2001). According to Fig 2 impedance spectroscopy a) bare GCE, b) the PSAA / GCE, c) the TB / PSAA / GCE, d) Au / TB / PSAA / GCE, and e) anti-CEA/Au/TB/PSAA/GCE modified electrode impedance shows the spectra. Electron transfer resistance showed a decrease, in the presence of Ferri/Ferro redox probe, TB and Au's.

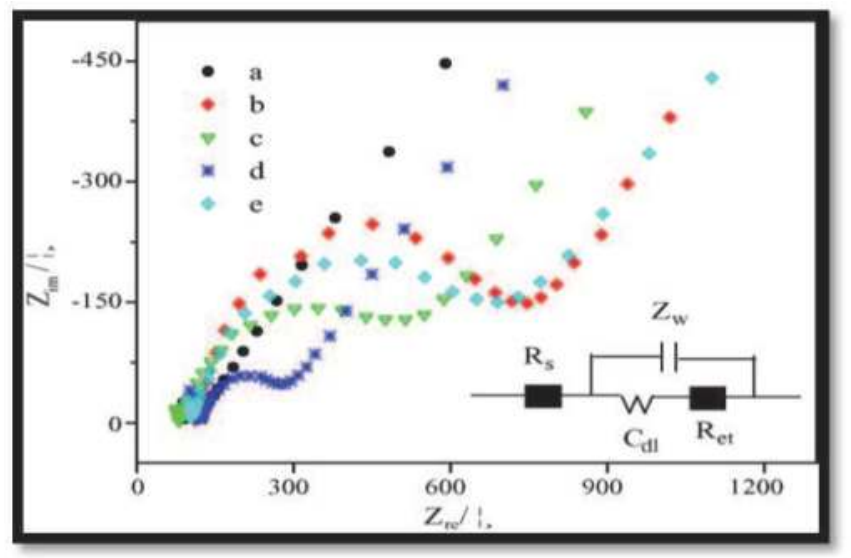

Fig. 2. Electrochemical impedance spectrums of glassy carbon electrode modified by polysulphanilic acid (Li et al., 2005)

It has been reported to the $\mathrm{CV}$ peaks increases in peroxide reduction when cyclic voltammetry studies of $\mathrm{HRP}$ in $\mathrm{H}_{2} \mathrm{O}_{2}$ solution. Incubation with $\mathrm{CEA}$ resulted in the reduction of $\mathrm{CV}$ peak current. The center of the electron transfer mediator in the formation 
of Immunocomplex blocked impedance and CV studies has been proven again. In this system, the biosensor preparation strategy is based on electrostatic interactions, control of $\mathrm{pH}$ during preparation is considered to be very important. In addition, the $\mathrm{pH}$ of the enzyme can cause a change in the operation and characteristics of $\mathrm{TB}$, the mediator. BSA and HRP As a blocking agent to prevent non-specific binding on prepared biosensors of two different proteins and their performances were compared. HRP was used the linear measurement range of the CEA were between 0.5 to $5 \mathrm{ng} / \mathrm{mL}$ when BSA was used 0.8 to 5 $\mathrm{ng} / \mathrm{mL}$. Lower determination limit of $0.2 \mathrm{ng} / \mathrm{ml}$. X. Li et al. developed instead of BSA as blocking agent, the use of HRP, the system has become more sensitive. CEA determination of $\mathrm{H}_{2} \mathrm{O}_{2}$ in the environment didn't show a differentiation of both blocking agent. Selectivity experiments in the studies with the AFP and hepatitis B, $2.38 \%$ and $3.24 \%$ RSD values, respectively. 20-day storage stability test of immunosensor, 20th day $97.5 \%$ initial activity remained at the end of the day persent.

Z. Liu et al. developed an immunosensor system was modified nano-Au/PTC-NH2/PB biocompatible composite film and CEA were determined by the composite film forming. High chemical stability of the system, a well-known redox characteristics of Prussian Blue was chosen because it is advantageous in terms of low price, and magnetic properties(Xian et al., 2007). Some of the disadvantages of immobilization on the surface of the PB electrode is noticeable. Among these various techniques, electrode surface immobilized PB(Zakharchuk et al., 1995; Mario et al., 2003; Lupu et al., 2002, Yu et al., 2007) depending on the electrode surface leakage to the solution(Haghigi et al., 2004, Yuan et al. 2007). In this study, a new organic compound was synthesized to create a semiconductor film. With ethylene diamine 3,4,9,10-perilentetracarboxylicanhydrite selective and sensitive to the formation of a layer of PTC-NH2 formed. Because of the well-known electronic properties of PTCDA (Gustafsson et al., 2006; Forrest, 1997) investigated the advantages of the production of a new substance derived in this matter. PTC-NH2 in the gaps on the creation of the PB film of organic-inorganic moved to create a component that has led to the surface because of the abundance of the amino ends of the leakage is prevented. Another advantage brought on the AuNPs, adsorbed by aminogroups, high specific surface area and lead to amplification of the response of the sensor by creating a structure that is biocompatible. Nano-Au / PTC-NH2/PB/GCE electrode of the recent anti-CEA-treated with BSA to prevent nonspecific binding. Impedance and $\mathrm{CV}$ datas were used to investigate for electrode interface. Modification of the electron transfer to the PB resistence reduced with the PTC$\mathrm{NH} 2$ modification as a result of increased resistance. Modification with anti-CEA increased resistance so successfully. For electrochemical sensor prepared and covalent bond-free Immunosensors effecting parameter was $\mathrm{pH}$. The temperature is also a defective factor that denatured biomolecules. Prepared immunosensor for CEA determination in linear range is between 0.05 to $2 \mathrm{ng} / \mathrm{mL}$ and the lower limit of determination is $0.018 \mathrm{ng} / \mathrm{mL}, \mathrm{R}^{2}=0.995$. Selectivity experiments carried out with the hepatitis B antigen, CEA, AFP, ascorbic acid, Lcysteine, L-lysine, L-glutamic acid and 1.4\% BSA, CV experiments showed that this differentiation is also acceptable. 60-day storage stability of the prepared immunosensor observed and RSD value is $4.1 \%$. Liu et al. developed by the PTC-NH2 compound produced in this system by increasing the stability of PB increased the accuracy of the method. Consequently lower limit of determination, and the fabrication steps produced quite simple. Song et al. developed an immunosensors system for the determination of CEA to interface the gold nanoparticles and Prussian Blue with the nanoparticle/nanocomposite multi-layer structure. Advantage of this system nanomaterials and composite forms based on made of 
chitosan and the immobilization of gold nanoparticles and multiwalled carbon nanotube (MWCNT) interface was used. MWCNTs are widely used in recent years because of high chemical stability, good electronic properties and mechanical stabilities(Wang and Musameh, 2003). MWCNTs can not show dissolution most of the features in environments containing water, to facilitate the dissolution of chitosan(CS) utilized in this study(Lu et al., 2005). In this way, the CS-MWCNT nanocomposite have shown very good agreement for potential applications(Liu et al., 2008, Spinks et al., 2006). In this way, the CS-MWCNT as a result of modification of amino groups on chitosan AuNP binding brought in a structure that allows for the convenience, the sensitivity of the system with a combination of both MWCNT and AuNPs were increased. Showing the redox activity of immune molecules are mostly used in the analysis of protein analysis, amperometric, redox activity of the PB in this study were chosen because of the well-known properties(Fiorito et al., 2005, Zhang et al., 2007). MWCNTs were activated by acid solution and then mixed in an ultrasonic bath CS and AuNPs after this stage of the nanocomposites structure formed. Liu et al. Synthesized PBNPs according to the method developed by(Liu et al., 2002). In this study, using the CSMWCNTs-AuNPs-PBNPs as redox probe modified composite structure was immobilized on the AuNPs and nitrile groups by electrostatic interactions. CS-MWCNTs-AuNPs solution of suspension was spread on the GCE electrode after the modification of GCE-PBNPs was performed with the above principle. BSA used to block non-specific binding of anti-CEA solution was prepared by immersion and $\mathrm{CV}$ measurements confirmed that the immobilization of impedimetric as expected. Developed Immunosensors system of linear measurement range 0.3 to $120 \mathrm{ng} / \mathrm{ml}$ range, $\mathrm{R} 2=0.9976$, and the lower limit of determination $0.1 \mathrm{ng} / \mathrm{mL}$. The best results are given for sensitivity, specificity and reproducibility. Song et al. were developed an anti-CEA/AuNPs/PBNPs/CS-MWCNTs-AuNPs/GCE modified electrode system in this study. By increasing the surface area of nanocomposite structure with PBNPs of the amount of the substance and the immobilization increased sensitivity and leakage could be prevented and thus can be used for clinical studies.

Y. Wang et al. Developed a Molecular imprinting-based potentiometric sensor system for the determination of cancer biomarker. Molecular imprinting process that artificial materials use of a very large area of the molecules determine to use(Pauling, 1940; Sellergren, 2001; Piletsky et al. 2001; Cram, 1988; Bartsch \& Maeda, 1998; Mosbach, 1994; Sellergren \& Shea, 1994; Haupt, 2003; Vlatakis meat al., 1993; Wulff, 1995). Used on a layer of polymer molecule imprinting method according to pattern creates a cavity, cavity's geometric pattern that is similar to the properties of the molecule carrying the groove to be connected. SAM is used as a surface molecular imprinting in this system. As the hydrophobic and hydrophilic groups of the SAM shown to interact with protein domains. Gold-coated silicon chip technique on a Au-S bond via alkenthiol molecules containing hydroxyl end is connected to water, this may very well organized in a single layer(Porter et al., 1987, Bain et al., 1989). If the target molecule to the surface during the binding of this molecule in the formation of monolayer taking place within the matrix of SAM forms imprinted. As a result of the removal of the mold layer also leaves behind a cavity. In terms of surface molecule template is compatible with the appropriate specificity by showing mold cavity is connected to the molecule performs and thus measured. The amount of potential to change the amount of binding molecule with the environment, as a result of decreasing the measured potentiometrically(Janata, 1975). Surface characterization studies performed by XPS and AFM. This study was carried out to determine CEA in colorectal cancer cell cultures. Linear determination is between 2.5 and $75 \mathrm{ng} / \mathrm{mL}$. Specificity studies of the electrode response 
were observed in an experiment with bovine hemoglobin. While the normal human cell cultures in the system of measurement used in the CEA and CEA than the amount of excess. CEA concentration increase not only determines the speed, but also increases the potency increases differentiation. The sensor response time were obtained in 1 hour. If the protein is smaller than the thickness of the SAM molecule, the mold is only a small portion will be sufficient to interact(Porter et al., 1987, Boehm et al., 1996; Brayer et al., 1995). Both the hydrophobic and hydrophilic surface of CEA(Duffy, 2001;) and gold adsorption ability of proteins(Ostuni et al., 2001; Hook et al., 1998, Kaufman et al., 2007, Tang et al., 2004) with a molecular shot has to be strong.

Vismanathan et al. Developed a MWCNT and liposome technique for the determination of CEA was prepared by using ferrocene to screenprinted electrode system developed with the use of single-use electrochemical Immunosensors. Recently, on the screen printed electrodebased electrochemical immunosensors extremely useful, because of designed for single use and portable use(Valat et al., 2000, Wu et al., 2006, Gao et al., 2003). Nanomaterials, especially carbon nanotubes, have high strength, thermal and electrical properties because of the very useful, biosensor immobilization materials that increase the limits of sensitivity (Hansen et al., 2006, Pathak et al., 2001). Vismanathan et al. CEA levels in serum and saliva was arrested in his study polietilenimin Screen Printed MWCNT modified electrode and ferrocene carboxylic acid, encapsulated CEA were used in liposomes. Ferrocene labels used in preparation of liposomes were prepared by the method of reverse phase to blow (Ho and Hsu, 2003; Ho and Huang, 2005; Ho et al., 2007). Liposomes dipalmitoil phosphatidylcholine(DPPC) and phosphatidyl dipalmitoil glycerol (DPPG) have been prepared. Thiolat groups, where created on the liposomes, were incubated with CEA and unreacted thiol groups were blocked by the etilenmaleimid. Carboxylic acid, sulfuric acid and nitric acid oxidized MWCNT functionalize MWCNT was obtained(Tseng et al., 2007). PEI was modified with MWCNT suspension drops on the SPE. Modified electrode was immobilized covalently antibodies with glutaraldehyde. Non-specific binding ends of the unreacted aldehyde prevented by BSA. Liposomes were created to be characterized by determining the homogeneity of the lipid results were obtained from each liposome(eq 1). $\mathrm{aL}$ per lipid head group surface area, $\mathrm{d}$ is the hydrodynamic radius, $\mathrm{t}$ the thickness of the lipid bilayer (Singh et al., 1996).

$$
\mathrm{N}_{\mathrm{tot}}=\frac{\pi}{a L}\left[d^{2}+(\mathrm{d}-2 \mathrm{t})^{2}\right]
$$

Thus, the number of CEA on the liposome can be calculated theoretically. From these data, the lipid molecule is connected to the CEA, 2 or 3. As a molecule of about 3900 that correspond to molar 0.023 . One was entrapped in a liposome, the liposome containing ferrocene $1 \times 10^{13}$ to 0.2 $\mathrm{M}$ was calculated for per milliliter. MWCNT on the negative ends of the positively charged PEI chains were interacted. Thus, measuring the limits of the modified electrode $5 \mathrm{pg} / \mathrm{ml}$ and $500 \mathrm{ng} / \mathrm{ml}$, respectively. Reproducibility of immunosensor to submit actual samples for accurate determinations shows promise in clinical trials is available

Xiang et al. have developed a ultrasensitive CEA immunosensor stratified layer by layer to determine the multi-enzyme system. In this study with the creation of multi-enzyme layer on the SWCNT with an increase of the enzymatic reaction to enhance signal. LBL (layer-bylayer) will be marking technique, allows to the amounts enzyme catalytic activity to an increase in the signal(Munge et al., 2005, Wang et al., 2006, Zhao and Ju, 2006). On the other hand the connection of multi-layer enzyme dramatically increases the analytical 
signal(Limoges et al., 2008; Limoges et al., 2006, Bauer et al., 1996; Schelde et al., 2001 and Mak et al., 2003, Kwon et al., 2008). Primarily on the preparation of SWCNT multienzyme LBL layer was prepared by modification of immunosensor(Munge et al., 2005, Zhou and Zhang, 2009). Alkaline phosphatase was immobilized on SWCNT has been modified with PDDA. SWCNT-(PDDA / ALP), conjugation was repeated several times, and thus the same system SWCNT-(PDDA / ALP) 4 bioconjugate the structure formed. This was adsorbed on PDDA conjugates negatively charged layer by repeating the same step again to add ALP binding immunosensors $\mathrm{Ab}_{2}$ was formed. GCE electrode surface was modified with immobilization o-ABA solution was prepared containing $\mathrm{H}_{2} \mathrm{SO}_{4}$ (Preechaworapuna et al., 2008). Reactive carboxylic Nb1 ends activated NHS, EDC after the modified electrode was treated to blocked by ethanolamine. After SWCNT-(PDDA-ALP) $)_{4}-$ PDDA-PSS-AB $_{2}$ bioconjugates was immobilized on electrode surface. ALP's isoelectric point is above this point will be charged pozitively easily adsorbed by PDDA. Enzyme layers by increasing the limit of determination decreased to very low values of the signal also increased the use of coenzyme is as follows: 0.1 to $1000 \mathrm{pg} / \mathrm{mL}$ defined as linear, the lower limit of determination in the FMA has dropped to 0.2. Specificity studies of myoglobin and lyzozme are not experienced a significant increase immunosensor responce these experiments also showed that high selectivity. Immunosensor's RSD value is $6.9 \%$ in the good results showed that the reproducibility and accuracy. As a result of prepared immunosensor for clinical trials because of it is quite susceptible to use the results. Table 2 summarizes the electrochemical immunosensors used for detection of CEA below.

\begin{tabular}{|c|c|c|c|c|}
\hline \multicolumn{5}{|c|}{ Table Of Electrochemical Transducers For Detection Of CEA } \\
\hline $\begin{array}{l}\text { Measurement } \\
\text { Technique }\end{array}$ & Immobilization Technique & $\begin{array}{l}\text { Low } \\
\text { Detection } \\
\text { Limit }\end{array}$ & $\begin{array}{l}\text { Lineer } \\
\text { Detection } \\
\text { Limit }\end{array}$ & Reference \\
\hline Amperometric & $\begin{array}{c}\text { anti-CEA/ PEI/Nafyon- } \\
\text { AuNP/Fec/ }\end{array}$ & $0.01 \mathrm{ng} / \mathrm{mL}$ & $\begin{array}{c}0.01 \text { to } 150 \mathrm{ng} \\
/ \mathrm{mL}\end{array}$ & $\begin{array}{l}\text { Shi and Ma, } \\
2011\end{array}$ \\
\hline $\begin{array}{l}\text { Voltammetric } \\
\text { And } \\
\text { Impedimetric } \\
\end{array}$ & $\begin{array}{c}\text { anti-CEA / Au / TB / } \\
\text { PSAA / GCE }\end{array}$ & $0.2 \mathrm{ng} / \mathrm{mL}$ & $\begin{array}{c}0.5 \text { to } \\
5 \mathrm{ng} / \mathrm{mL}\end{array}$ & Li et al., 2006 \\
\hline Voltammetric & $\begin{array}{c}\text { Anti-CEA-BSA/Nano-Au } \\
\text { / PTC-NH2/PB/GCE }\end{array}$ & $0.018 \mathrm{ng} / \mathrm{mL}$ & $\begin{array}{c}0.05 \text { to } 2 \mathrm{ng} / \\
\mathrm{mL}\end{array}$ & Liu et al., 2008 \\
\hline Voltammetric & $\begin{array}{c}\text { anti- } \\
\text { CEA/AuNPs/PBNPs/CS- } \\
\text { MWCNTs-AuNPs/GCE }\end{array}$ & $0.1 \mathrm{ng} / \mathrm{mL}$ & $\begin{array}{l}0.3 \text { to } 120 \\
\mathrm{ng} / \mathrm{mL}\end{array}$ & $\begin{array}{l}\text { Song et al., } \\
2010\end{array}$ \\
\hline Potentiometric & $\begin{array}{l}\text { SAM-CEA/Au Electrode } \\
\text { Molecular Imprinting }\end{array}$ & $2.5 \mathrm{ng} / \mathrm{mL}$ & $\begin{array}{c}2.5 \text { to } \\
75 \mathrm{ng} / \mathrm{mL}\end{array}$ & $\begin{array}{l}\text { Wang et al., } \\
2010\end{array}$ \\
\hline Amperometric & $\begin{array}{l}\text { MWCNT and ferrocene } \\
\text { labeled liposome on SPE }\end{array}$ & $5 \mathrm{pg} / \mathrm{mL}$ & $\begin{array}{l}5 \mathrm{pg} / \mathrm{mL} \text { to } \\
500 \mathrm{ng} / \mathrm{mL}\end{array}$ & $\begin{array}{l}\text { Vismanathan } \\
\text { et al., } 2009\end{array}$ \\
\hline Amperometric & $\begin{array}{l}\text { SWCNT-(PDDA / ALP) } 4^{-} \\
\mathrm{Ab}_{2}\end{array}$ & $0.1 \mathrm{pg} / \mathrm{mL}$ & $\begin{array}{c}0.1 \text { to } 1000 \mathrm{pg} \\
/ \mathrm{mL}\end{array}$ & Xiang et al., \\
\hline
\end{tabular}

Table 2. Electrochemical Immunosensor for Detection of CEA 


\subsubsection{Electrochemical immunosensors developed for the detection of CRP And TNF}

C-reactive protein is a biomarker that is $118 \mathrm{kDa}$ and is circulating in the blood, the biomarker synthesized by interlokin6, in the liver (http://www.scrippslabs.com/datatables/proteinabsorbance.html, 2007; Weinhold and Rüther, 1997). Plasma levels are lower than normal human, $3 \mu \mathrm{g} / \mathrm{mL}$ (Hu et al., 2006; Verma and Yeh, 2003). Used to determine levels of CRP as a prognostic indicator of gastric cancer.

M.-H. Lee et al. developed the source and drain electrodes placed on the surface potential measurement was carried out under a layer of semiconductor SiNW field-effect transistors in the system. Nanotechnology-based sensors through the mechanisms determining the limits and sensitivity have increased in recent years nested. Direct labeling of biomolecules and nano-structures provide an ultra-sensitive manner possible to determine. Foundations this type SiNW Fet transistor and connecting the surface of the positive or negative charge on the surface accumulation of a protein based on the principle of conductivity decrease or increase(Patolsky et al., 2006). This mechanism allows the realization of high sensitivity and real-time measurement. In this study, silicon nano-wires single-crystal substrates were prepared according to the method of thermal oxidation of p-type substrate, $n$ type substrate and n-type substrate to face grain orientation(Lee et al., 2007). Gold colloids were prepared reduction of sodium citrate(Frens, 1973). Aldehyde-ended single-layer surface modification of SiNW surface is the principle of creation. In general, the use of oxygen plasma as a chemical reaction of the hydroxyl group is based on creating a glutaraldehyde solution(Patolsky et al., 2006). In this study, oxygen plasma cleaning to be surrounded by the surface amine performs a mapping of the surface silanol. Then aldehyde groups formed and paired with CRP bound to the antibody on the created surface. CRP and CRP antigen SiNW after reaction with gold nanoparticles formed to conjugate. This system is designed to work in a flow system, containing two PDMS micro-pump system, created a flow to input and output channels, microchannels 600 micrometers in length in the flow of the system by performing the analysis of the protein has led to measurement area. In this study, the actual serum samples from patients were used. Isoelectric point of CRP between 5 to 6, which is negatively charged in solution is neutral for this reason, flow to p-type SiNW Fet. Previous studies which Fet SiNW are used, to determine the lower limits of s have dropped to $1 \mathrm{fmole}$. In addition, the observing effect of sodium chloride in the SiNW youth initiative. 13 CRPpositive patients, the diagnosis of gastric cancer biomarkers combined CEA and CA19-9 can be determined. Measurements of serum donors SiNW Fet between 3.2 to 10.4 micrograms/milliliter were measured. Despite the biomarkers measured in this system of measurements to be made so sensitive that low sensitivity of the system determines limitations. According to the results presented in this SiNW Fet signals proportional to the levels of CRP. Therefore, the diagnosis of gastric cancer, especially in the early stages, the determination provides a great asistance.

Qureshi et al. was developed Immunosensors system by using unlabeled array capacitors combined with gold for the determination of multiple biomarkers will be integrated biosensor systems have evolved to the surface of silicon oxide. Capacitive immunoassays are phenomenon immunochemical tests in recent years, the development and manufacture of hand-held devices used for personal use. Affinity-based capacitive sensors that can respond to even very low levels the opportunity to direct analyte measurement techniques. Changes in dielectric properties of the measurement basis on or load distribution depend on the conductivity change in the exchange of antigen-antibody interaction on the surface of the electrode. Recently, the label was developed the redox mediator used in capacitive 
biosensors in this system(Carrara et al., 2009; de Vasconcelos et al., 2009; Saravan et al., 2008). In this study, the covalent bonding on an optimized GID is connected antibodies via epoxy-silanisation(Saravan et al. 2008), this method is less prone to sensitivity, the other less cheap silicon dioxide with a high-sensitive measurement applied to nanocrystalline diamonds(Quershi et al. , 2009). GID arrays of silicon oxide surface with a thick layer of tungsten, first a thin gold layer is coated in advance to allow for the creation of an easier way. According to this structure, the capacitor arrays includes 24 fingers GID(Quershi et al., 2010). First, arrays were treated with MPA to SAM created layer free carboxyl groups was activated by NHS / EDC and antibody is ready for immobilization. Phase of antibody immobilization was created in two formats: the first method, each GID capacitor with a pure antibody, while the second method, equal amounts of multiple antibodies (CRP, TNF and IL-6) was co-immobilized. Dielectric parameters of different antigens were treated arrays were prepared. BSA was used as a non-specific protein for a negative control. Limits for the determination of biomarkers measured in linear; $25 \mathrm{pg} / \mathrm{mL}$ to $25 \mathrm{ng} / \mathrm{mL}$. The complex dielectric constant is a result of the change in dipole momenttes of biomolecules which differences amino acid sequence of elements that can bring about change in the dipole momentte(Antosiewicz, 1995). To the determination of several biomarkers of cancer as it is known to determine the accuracy of diagnosis of cancer is increasing. Most of the other proteins secreted as a result of the cancer biomarker can be found in a unified manner. Quareshi et al. developed for multiple analyses by allowing the disease to other singleanalyte immunosensors advantageous and gives accurate results in this array technology. In addition, the silicon oxide background is fast, simple and sensitive measurements, allowing the hand-held personal devices allows the development of diagnostic devices. Table 3 summarizes the electrochemical biosensors for analysis of CRP and TNF.

\begin{tabular}{|c|c|c|c|c|}
\hline \multicolumn{5}{|c|}{ Table Of Electrochemical Transducers For Detection Of CRP and TNF } \\
\hline $\begin{array}{c}\text { Measurement } \\
\text { Technique }\end{array}$ & $\begin{array}{c}\text { Immobilization } \\
\text { Technique }\end{array}$ & $\begin{array}{c}\text { Low Detection } \\
\text { Limit }\end{array}$ & $\begin{array}{c}\text { Lineer } \\
\text { Detection Limit }\end{array}$ & Reference \\
\hline Potentiometric & Anti-CRP/SiNW Fet & $3.2 \mu \mathrm{g} / \mathrm{mL}$ & $\begin{array}{c}3.2 \text { to } 10.4 \\
\mu \mathrm{g} / \mathrm{mL}\end{array}$ & Lee et al., 2010 \\
\hline Capacitance & $\begin{array}{c}\text { Anti-CRP/MPA/Au } \\
\text { Electrode }\end{array}$ & $25 \mathrm{pg} / \mathrm{mL}$ & $\begin{array}{c}25 \mathrm{pg} / \mathrm{mL} \text { to } \\
25 \mathrm{ng} / \mathrm{mL}\end{array}$ & $\begin{array}{c}\text { Qureshi et al., } \\
2010\end{array}$ \\
\hline
\end{tabular}

Table 3. Electochemical Immunosensor For Detection of CRP

\subsubsection{Electrochemical immunosensors developed for detection of PSA}

Prostate cancer is one of the most common cancers in men in most types of cancer among the three leading causes of death (Jemal et al., 2006). For this reason, the most important part of treatment of the disease is diagnosed early. Early detection of protein-based biomarkers for biosensor technology in the last few years as it is known to be very beneficial for the early diagnosis of determination. Prostate-specific antigen (PSA), to determine the most common tumor marker is used on prostate cancer(Benson et al., 1992, Bradford et al., 2006; Brawer, 1999, Stephan et al., 2006). PSA is a glycoprotein of 32-33 kDa single chain (Landis et al., 1999, Cesar et al., 2004;), a part of $93 \%$ sugar residue peptide also contains the rest of it is produced by the prostate tissues(Loeb and Cantolona, 2007). 
Y.-Y. Lin et al. developed an immunochromatographic/electrochemical biosensor system which is nanoparticle-labeled for the determination of the PSA. This study obtains two steps; the first step rapid immunochromatographic assay with a combination of simple and sensitive immunoassay with a diagnosis after the device. As is well known a specific binding substance chromatography after moving from the principle of signal, depending on the diagnosis has been developed. Very fast measurement system offers the possibility of one or two minutes. In the first part of the design is based on the visual judgement, by using a dye or a gold nanoparticle provides a quick and qualitative determination (Jin et al., 2005; Nagatani et al., 2006, Zhang et al., 2006, Fernandez-Sanchez et al., 2005) . But not only is not sufficient for the qualitative determination of the correct results therefore reveal its high sensitivity due to the sensitivity of a combined electrochemical immunoassays permit designed to provide a more accurate result. Advantages brought by nanotechnology in recent years began to develop nanoparticle-based Immunosensors thus increase the signal trace of biomarkers to identify and obtain a more precise measurement is possible(Georganopoulou et al., 2005; Huhtinen et al., 2004; Jain, 2005, Liu et al., 2006, Liu and Lin, 2007, Liu et al., 2007, Nam et al., 2003, Wang et al., 2006). Y.-Y. Lin et al. developed to increase the signal in this system made of CdSe @ ZnS quantum dots (QDS) are used to mark the anti-PSA antibodies. Quantum dots can contain hundreds of very useful particles and biocompatible terms of marking, and signal enhancement. In order to take the measurement Y.-Y. Lin et al. anti-PSA-QD prepared (Wu et al., 2007; Wang et al., 2008). Then, immunochromatographic/electrochemical biosensor prepare, the system includes immunochromatographic strip and this strip is composed of three parts; sample loading area, the second part of the anti-PSA-QD loaded contact area, the third of the area consists of covalently bound anti-PSA to Screen Printed electrodes were placed under the test area. Modifications by using diaminothiofen to form the membrane with the space arms. Thus, the modified nitrocellulose membranes were later activated by glutaraldehyde, then incubated with the anti-PSA solution. Horizontal flow in the system, BSA and Tween blocking dried using a membrane with $\mathrm{N}_{2}$ gas. Anti-PSA-QD conjugates were dried by applying the last part of the glass fiber. PSA application of this system was performed in various advantageous immunochromotographic primarily be facilitated removal of the extra buffer, other advantage, ten minutes of the measurement is performed. CdSe quantum dotls created the nucleus and shell contains ZnS. The sample is applied to the system as part of the walk by the PSA QD-labeled anti-PSA-QD complex consists of an complex. Membrane was adsorbed on the anti-PSA-QD bound to act on the membrane with anti-PSA to PSA, which itself depends on covalent, QD marked when the test section consists of a sandwich complex. Here, an appropriate reaction $(1 \mathrm{M} \mathrm{HCl})$, QD complex is dissolved and the remaining free cadmium ions in the electrochemical measuring system to provide to be quantify. This system is ideally suited for making quantitative measurements and the signal gain is proportional to the amount of the PSA. PSA's linear measuring range between 0.05 to $4 \mathrm{ng} / \mathrm{mL}$ in this system and $\mathrm{R}^{2}=0.995$ was determined. RSD value of reproducibility was $6.4 \%$ and the lower limit of determination of $0.02 \mathrm{ng} / \mathrm{ml}$. This combined and developed system is cheap, fast and sensitive due to the use of devices developed for clinical applications, and paved the way for personal use.

J.F. Rusling et al. developed electrochemical sensor technology by other nanomaterials have been used. As is well known properties of carbon nanotubes are extremely useful materials that show metallic or semiconductivity (Munge et al., 2005). SWCNTs were used in the sensor at the two stages; electrode surface with higher conductivity and higher surface area 
to provide more adhesion to the surface with analyte signals to be more sensitive and are used to mark the second part, by moving a larger amount of enzyme, and secondary antibodies amperometric signal is used as to increase(Mung et al., 2005). In this study, the surface of the carbon nanotube electrode has been modified by creating forest. SWCNT on the surface to be more intense forest electrode coated with a thin film layer nafyon. The second stage used for the oxidation of carbon nanotubes formed by acid carboxyl ends of the enzyme, peroxidase, and secondary antibody was immobilized. According to this approach, the CNT in each 100nm enzyme are 170 HRPs (Jensen et al., 2008). This also provides a determination of ultra-low levels of PSA (4 pg / ml) (Yu et al., 2006). Limitations of the generated results were extremely sensitive for nantube forests. The fact that nanotubes together with separation is difficult and increasing heterogeneity among the problems to be tackled. Depending on these results, Rusling et al. nanoparticles modified electrodes have deposited layer by layer(Lvov, 2001). First a polycationic molecule immobilized on ultrathin pyrolytic graphite electrode surface, after a negatively charged gold nanoparticles were immobilized. In the preparation of the negatively charged AuNPs modified with AuNPs glutatyondaki glutathione cysteine and glycine with glutamic acid at the carboxyl ends of the gold bond to make out the orientation created by the nucleus (Zheng and Huang, 2004). Carboxyl ends of the surfaces of nanoparticles created by HRP conjugate binding to form an amide bond with the HRP. This structure responds to a previous study, an electrochemical $0.28 \mu \mathrm{A} / \mu \mathrm{Ml} 1 \mathrm{k} 0.18 \mu \mathrm{A} / \mu \mathrm{M}$ health changes in more than $40 \%$. Detection limit of the results showed that more than 3 times. These two tests on samples of infected people in the experiments showed a good correlation with ELISA tests. This study showed that the province of AuNP with nanomaterials, especially with the system established SWCNT due to the sensitivity and accurate results have proven that they are suitable for clinical studies. The biggest problem with layers of polymer systems with non-specific binding problem should be in front of non-specific binding.

Wei et al. developed an immunosensor system by electrochemical measurement of the amount of PSA performed using $\mathrm{Au}-\mathrm{Fe} 3 \mathrm{O} 4$ nanoparticle labels. In this study, gold nanoparticles on a metal oxide support in support of holding a synergistic effect between metal and metal oxide showed higher catalytic activity(Valden et al., 1998, Wang et al., 2009, Zheng and Stucky, 2006; Comotti et al., 2006 ; Liu et al., 2006, Lee et al., 2010a). Similarly, Wang et al. their study of the structure of $\mathrm{Pt}-\mathrm{Fe} 3 \mathrm{O} 4$ showed higher catalytic activity than single PtNPs determined (Wang et al., 2009b). In this study, dumbbell-like $\mathrm{Au}-\mathrm{Fe}_{3} \mathrm{O}_{4}$ was used to perform catalysis synergistic effect on $\mathrm{H}_{2} \mathrm{O}_{2}$. Created a dumbbell-like $\mathrm{Au}-\mathrm{Fe}_{3} \mathrm{O}_{4}$ on the secondary antibody binding to PSA measurement was carried out. Immobilization on the surface of the electrode material used a graphene layer in this study. Carbon atoms of graphene layers tightly packed, flat two-dimensional honeycomb-like, with a high surface area nanomaterials(Geim and Novoselov, 2007, Ohta et al., 2006; Aleiner and Efetov, 2006). Because of these features of graphene layers increases the surface area of the installation of the primary antibodies, showing a good conductivity of $\mathrm{H}_{2} \mathrm{O}_{2}$ helps to determination(Du e al., 2010). Graphene layers of graphite oxide was prepared by the method of thermal exfolation(McAllister et al., 2007). Graphite oxide, graphene has been modified according to the method Hummer(Liu et al., 2008). Au- $\mathrm{Fe}_{3} \mathrm{O}_{4}$ dumbbell-like particles, Lee et al. prepared and developed method(Lee et al., 2010a) into the secondary antibody solution was added to conjugation. Graphene layers are created on the carboxyl groups with amide bonds linked with anti-PSA (primary antibody) was created with the GS-conjugate-anti-PSA, BSA was used to generated non-specific binding of conjugate to avoid dropping the surface of GCE. 
On the modified electrode was incubated with PSA at the end on the previously prepared were incubated with the addition of $\mathrm{Au}-\mathrm{Fe}_{3} \mathrm{O}_{4}-\mathrm{AB}_{2}$. Peroxide electrode was prepared by adding the signal from the $\mathrm{Au}-\mathrm{Fe}_{3} \mathrm{O}_{4}$ structure as a result of peroxide reduction by the amount of PSA was measured. The amount of PSA in the system increases, the increase in flow has occurred. Bi-linear system, the measurement of PSA concentration in the range 0.01 to $10 \mathrm{ng} / \mathrm{mL}$, calculated as the lower limit of determination was found to be $5 \mathrm{pg} / \mathrm{mL}$. According to Wei et al. there are three factors to determine low amounts that are based on the large surface area of graphene layers has increased the installation of the primary antibody, $\mathrm{Au}-\mathrm{Fe}_{3} \mathrm{O}_{4}$ dumbbell-like particles as a result of the high value of the catalytic reduction of peroxide increased the conductivity of the layers with the creation of very efficient in terms of lower limits were determined. 6.3\% RSD value of the system is determined, the electrode stability is due to the long-term stability of the NPS Au-Fe $\mathrm{O}_{4}$. The same procedures developed with the ELISA method is less than the deviations between the values was observed compared Immunosensors. As a result, the GS large surface area, high stability and catalytic activity of $\mathrm{Au}-\mathrm{Fe}_{3} \mathrm{O}_{4}$ particles of the system has to be sensitive.

$\mathrm{N}$. Triroj et al. developed miniaturized nanoelectode arrays with microfluidic biochemical analysis of the PSA sensor technology. As is well known properties of nano-sized materials due to different measurement systems are developed extremely sensitive, fast and easy. For instance, the interface in terms of molecular nano-electrodes are stable and electroactive molecules are easy to access the center for more sensitive measurements(Shi et al., 2007; Shi and Yeh, 2007; Kovochich et al., 2007, Yeh et al., 2007). This is small electrodes on the surface of the electrode double layer, increasing the loading materials and diffusion electrochemical reactions can be controlled more easily to make the execution. On the other hand, microelectrode surface facilitates the mass transport(Norton et al., 1990). High mass transfer is important because in this way; biomolecules to the electrode surface of the catalytic reaction as a signal to come together and this association creates the first condition can not be controlled by diffusion(Armstrong, 2005). The electronic transmission of uniform nano-sized electrodes plays a role in increasing signal. Micro-electrode platform, the previous configurations(Triroj et al., 2006) unlike in this study as working electrode between the electrode arrangement of a micrometer pore is designed to be $5 \times 5$ and $5 \mathrm{~nm}$. PSA determination for the design of microarrays as a sensor electrode surface is primarily the formation of the SAM procedure(Achim et al., 2009, Yeh et al., 2010a, b) which was carried out with mercaptopropionic acid. Free carboxyl ends of SAM layer activated by NHS / EDC, metallized peptide and nucleic acid-incubated with anti-PSA. PNA-ant-regulation of PSA(Achim et al., 2009, Yeh et al., 2010a, b) facilitated the immobilization of the electrode surface. After the surface of the microarray was incubated with PSA marked with GOx, this step was supported by CV datas. Because of the high surface area of microarray, the PSA levels in a sensitive way to be determined $4-10 \mathrm{ng} / \mathrm{mL}$. Such as the measurement of the enzyme suggests the preparation of the electrode marked with the signal extraction based on the conversion to glucose. Accordingly, the lower limit is determined as $10 \mathrm{pg} / \mathrm{mL}$.

$\mathrm{Qu}$ et al. developed immunosensor based on the marking technique with silica nanoparticles for determination of total PSA in human serum. Co-functionalized SiNPsantibodies with alkaline phosphatase measurement principle of silver electrodeposition measure of the PSA. Silicon nanoparticles have been prepared by the method of emulsion, Triton X-100 and hydrophilic silica nanoparticles formed by the addition of hexanol in the cyclo hexane (Qu et al., 2008). Solved by adding an appropriate amount of the nanoparticles in APTES, glutaric anhydride into the solution containing nanoparticles formed by adding 
functionalize silicon binding to ALP. Gold electrode was modified with cysteamine solution and the amino ends activated with glutaraldehyde that were incubated with the antibody, to prevent non-specific binding of aldehyde ends are blocked with BSA. The electrode made of silicon nanoparticles drops were modified for sandwich method. On this method, $0.76 \mathrm{ng} /$ $\mathrm{ml}$ PSA concentrations were determined in lower determination. ALP of the ascorbic acid 2phosphate conversion of electrons with the silver particles deposited on the surface of the stacked electrode and consequently the signal was measured. For increasing the catalytic activity of ALP as a result of the concentration increase has occurred in response to electrode. Excess amounts of ALP can help to prevent the sandwich method of attachment. $\mathrm{Li}$ et al. developed to detection of cancer biomarkers by using nitrodopamin (NDA) with functionalized $\mathrm{Fe}_{3} \mathrm{O}_{4}$ particles to increase the signal of the electrochemical determination of electrochemical immunosensor. The NDA system with a strong anchor agent is a material that for immobilization of iron oxide formed by capturing nanoparticles(Young et al., 2009). The immobilization material is used to bind both the primary antibodies and secondary antibodies. Thionine complex with $\mathrm{Fe}_{3} \mathrm{O}_{4}$ and created $\mathrm{HRP}-\mathrm{AB}_{2}$ in the presence of peroxide is the mediator with Thionine reduce the signal. $\mathrm{Fe}_{3} \mathrm{O}_{4}$ nanoparticles synthesized according to the method developed by $\mathrm{Xu}$ et al.(Xu et al., 2009). NDA was prepared according to the study of Malisova et al.(Malisova et al., 2010). NDA- $\mathrm{Fe}_{3} \mathrm{O}_{4}$ with the primary antibody was immobilized on the modified GCE. This action on the $\mathrm{NDA}-\mathrm{Fe}_{3} \mathrm{O}_{4}$ modified electrode was activated with glutaraldehyde and primary antibody binding blocked with BSA and the free ends of the steps to be included. After this containing the solution of PSA in different concentrations applied to the surface of the electrode and electrode was incubated for $1 \mathrm{~h}$. Finally, the separately prepared solution of NDA- $\mathrm{Fe}_{3} \mathrm{O}_{4}-\mathrm{TH}-\mathrm{HRP}-\mathrm{Ab}_{2}$ drops was measured. Because of HRP with a weak signal, $\mathrm{Fe}_{3} \mathrm{O}_{4}$ particles increased signal and shown better conductivity in this system. NDA can increase the loading of antibody and HRP has a positive effect on signal. NDA- $\mathrm{Fe}_{3} \mathrm{O}_{4}$ formation on the surface of the electrode, $\mathrm{CV}$ datas also shows that because of attachment the peak would give successfuly. Looking at the performance level of immunosensor, $4 \mathrm{mM}$ allows the determination of peroxide. This is accomplished to the use of TS as the mediator. NDA- $\mathrm{Fe}_{3} \mathrm{O}_{4}$ and $\mathrm{Fe}_{3} \mathrm{O}_{4}$ was prepared with the control experiment, two NDA conjugates shown better measurement limit than 5 times. This method is similar to the methods(Qu et al., 2008; Chikkaveeraiah et al., 2009, Yu et al., 2006, Liu et al., 2007) compared with measurements carried out have proven much more sensitive. The linear detection limit for PSA was in the range of 0,005 to $50 \mathrm{ng} / \mathrm{ml}$. These values fall into the range where the normal human values(Lilja et al., 2008). Sensitivity determination of immunosensor; IgG, BSA, a-1-fetoprotein (AFP) and glucose $8 \%$ of the trials showed less interference. Repeatability and reproducibility studies showed for this immunosensor that acceptable.

Yang et al. developed ultrasensitive immunosensor which is modified with a layer of graphene. Graphene layers are 2-dimensional structures with high surface area material that provides excellent conductivity and stability is described in previous studies. Graphene layers for this study is to make the system more sensitive to both the primary antibody immobilization and secondary antibodies. Primary antibody immobilization of the 1pyrenebutanoic acid adsorbed on graphene layers have been immobilized by using sucsinimidyl esters. п-п stacked with the primary antibody attached to the graphene layers on the suksinimidyl esters. In graphene layers of graphite oxide was prepared by the method of thermal extrafolation(McAllister et al., 2007). Secondary antibody binding stage on graphene layers are mixed with thionine by glutaraldeyde to built TH conjugates formed 
with the active aldehyde residues, on top of them are bond HRP and anti-PSA via aldehyde. Primary antibodies were adsorbed on the graphene-1-pyrenebutanoic acid; esters sucsinimdyl graphene layers are created with non-specific binding of BSA. This structure is attached to the PSA is about to be immobilized on the GCE, and lastly a conjugate addition of secondary antibodies were measured by sandwich method. CV scans showed that the addition of thionine to facilitate the electron transfer effect. According to Yang et al. there are three reasons for this immunosensor for showing high sensitivity, this can be high because it is a large amount of surface area of graphene layers with the binding of HRP and TH increased signal, HRP showed high catalytic activity and electron transport in graphene layers used for the increasing effect of mediator between the TS of the peroxide with HRP. Catalytic reaction occurs, the current increases linearly. Linear measurement of PSA concentration in the range 0.002 to $10 \mathrm{ng} / \mathrm{mL}$ were determined, lower determination limit is $1 \mathrm{pg} / \mathrm{ml}$, respectively. The obtained values showed a normal human and cancer patients fall into a range of standard values(Lilja et al., 2008). Depending on the sensitivity of the use of graphite oxide is used as the GS immunosensor 100 times faster than that observed. Children showed a narrower measure by graphite oxide is 0.2 to $2 \mathrm{ng} / \mathrm{ml}$. TH provided the reasons for this stability in the long time molecule layer on the graphene $\Pi-\Pi$ jam with increased stability of immunosensor, the secondary antibody and HRP on the GS in the covalent bonding increases stability. As a result, stability and conductivity of nanomaterials used in this study for the immobilization of molecules led to the introduction of ultrasensitive immunosensors.

According to Yang et al. developed another quantum dot functionalized graphene layers as a label by the employed for electrochemical immunosensor systems. Graphene layers wide surface/volume ratio is preferred because of the reasons stated in previous studies(Liu et al., 2010, Wu et al., 2010). Graphene layer immobilization of the study, the primary antibodies and secondary antibodies, QD functionalized graphene sheets are used for labeling. Designed of immunosensor on graphene layers of graphite oxide were prepared by the method of thermal extrafolation(McAllister et al., 2007). GS-QD-AB 2 conjugates to be done; QD CdCl 2 solution preparation stage in the mixed acid solution mercaptoundecanoik acid and $\mathrm{Cd}^{2+} \mathrm{GS}$ functionalized layer was created. Onto this conjugation $\mathrm{Na}_{2} \mathrm{~S}$ solution added when the CdS (QD) funtionalized GS consists of layers. Activated by NHS / EDC with secondary antibody that was prepared by adding layers of anti-PSA-QD conjugate to GS-formed. GS primary antibody reaction with the surface of the PBSE based amidation succinimidyl esters of secondary antibodies were carried out the immobilization via amine groups. BSA was used to block non-specific interactions. Secondary antibodies then bond to the PSA solution which was prepared after the electrode surface by applying the electrochemical measurement were ready. Having a large surface area of the GS with a lot of QD increased sensitivity. Electrochemical measurement principle depends on the determination of cadmium release from the system. PSA to be determined as a linear concentration range 0005 to $10 \mathrm{ng} / \mathrm{ml}$, the lower limit of determination at $3 \mathrm{pg} / \mathrm{ml}$. With low limits and $\mathrm{Cd}^{2}+$ ions to determine the QDS functionalized graphene layer is based on the determination by showing good conductivity. Graphene oxide layer was prepared with 50 times more sensitive than other immunosensor system. Repeatability of the electrode as the experiments was $7.9 \%$ RSD value. Selectivity studies, human IgG, BSA, lysozyme and glucose molecules are showing on the initiative of the experiments, the signal has changed by $7 \%$. Additionally, the accuracy of this immunosensor showed that good correlation with ELISA tests. In table 4, a summary for biosensors developed for detection of PSA is given below. 


\begin{tabular}{|c|c|c|c|c|}
\hline \multicolumn{5}{|c|}{ Table Of Electrochemical Transducers For Detection Of PSA } \\
\hline $\begin{array}{l}\text { Measurement } \\
\text { Technique }\end{array}$ & $\begin{array}{l}\text { Immobilization } \\
\text { Technique }\end{array}$ & $\begin{array}{l}\text { Low } \\
\text { Detection } \\
\text { Limit }\end{array}$ & $\begin{array}{l}\text { Lineer } \\
\text { Detection } \\
\text { Limit }\end{array}$ & Reference \\
\hline $\begin{array}{c}\text { Immunochromatog } \\
\text { raphic and } \\
\text { Electrochemical } \\
\end{array}$ & $\begin{array}{c}\text { anti-PSA- } \\
\text { QD/nitrocellulose } \\
\text { membranes } \\
\end{array}$ & $\begin{array}{c}0.02 \\
\mathrm{ng} / \mathrm{mL}\end{array}$ & $\begin{array}{l}0.05 \text { to } 4 \\
\mathrm{ng} / \mathrm{mL}\end{array}$ & $\begin{array}{l}\text { Lin et al., } \\
2011\end{array}$ \\
\hline Amperometric & $\begin{array}{c}\mathrm{Au}-\mathrm{Fe}_{3} \mathrm{O}_{4^{-}} \\
\mathrm{AB}_{2} / \mathrm{PSA} / \mathrm{GC}\end{array}$ & $5 \mathrm{pg} / \mathrm{mL}$ & $\begin{array}{l}0.01 \text { to } 10 \\
\mathrm{ng} / \mathrm{mL}\end{array}$ & $\begin{array}{l}\text { Wei et al., } \\
2010\end{array}$ \\
\hline Amperometric & $\begin{array}{c}\text { anti-PSA/ } \\
\text { PNA/GOx/MPA/Micr } \\
\text { oArray }\end{array}$ & $10 \mathrm{pg} / \mathrm{mL}$ & $\begin{array}{c}4 \text { to } \\
10 \mathrm{ng} / \mathrm{mL}\end{array}$ & $\begin{array}{l}\text { Triroj et } \\
\text { al., } 2011\end{array}$ \\
\hline Amperometric & $\begin{array}{c}\text { anti-PSA- } \\
\text { ALP/Cys/AuElectrode }\end{array}$ & $\begin{array}{c}0.76 \\
\mathrm{ng} / \mathrm{mL}\end{array}$ & $\begin{array}{c}1 \text { to } \\
35 \mathrm{ng} / \mathrm{mL}\end{array}$ & $\begin{array}{l}\text { Qu et al., } \\
2008\end{array}$ \\
\hline Amperometric & $\begin{array}{c}\mathrm{NDA}-\mathrm{Fe}_{3} \mathrm{O}_{4}-\mathrm{TH}-\mathrm{HRP}- \\
\mathrm{Ab}_{2}\end{array}$ & $\begin{array}{c}0,005 \mathrm{ng} / \mathrm{m} \\
\mathrm{L}\end{array}$ & $\begin{array}{c}0,005 \text { to } 50 \\
\mathrm{ng} / \mathrm{mL}\end{array}$ & $\begin{array}{l}\text { Li et al., } \\
2011\end{array}$ \\
\hline Amperometric & $\begin{array}{l}\text { Anti-PSA/HRP- } \\
\text { TH/PBA/GC }\end{array}$ & $1 \mathrm{pg} / \mathrm{mL}$ & $\begin{array}{l}0.2 \text { to } 2 \\
\mathrm{ng} / \mathrm{mL}\end{array}$ & $\begin{array}{l}\text { Yang et } \\
\text { al., } 2010\end{array}$ \\
\hline Conductance & GS-QD-anti-PSA & $3 \mathrm{pg} / \mathrm{ml}$ & $\begin{array}{c}0005 \text { to } 10 \\
\mathrm{ng} / \mathrm{mL}\end{array}$ & $\begin{array}{l}\text { Yang et } \\
\text { al., } 2010\end{array}$ \\
\hline
\end{tabular}

Table 4. Electochemical Immunosensors developed for Detection of PSA

\subsubsection{Electrochemical immunosensors developed for the determination of VEGF}

Vascular endothelial growth factor has an important role in tumor growth and a biomarker metastas. Inordinate amount of time metastasis of VEGF that is structure containing five glycoprotein and synthesized large amounts(Augustin et al., 2009). Receptor binding as a result of this biomarker of endothelial cells in tissue secreted the excitation function with cascade mechanism(Kranz et al., 1999; Kurebayashi et al., 1999; Ruohola et al., 1999, Zhai et al., 1999). Rapid proliferation of tumor cells to increased amount of VEGF production. Lung, thyroid, breast, gastrointestinal system, kidney and bladder cancer was observed when production increases (Ferrara and Davis-Smyth, 1997).

Prabhulkar et al. developed an amperometric immunosensors system for the determination of VEGF. Unfortunately, most of the signal can not be given by non-electroactive biomarker, for this reason the use of a marker and a further reaction must be performed by measurement. Developed in the measurement of VEGF in this system with ferrocene monocarboxylic acid used for labeling, ferrocene monocarboxylic acid was measured by using its well known electrochemical properties(Zhang et al., 2008). Ferrocene monocarboxylic acid is not given intermediate product of a molecule that can be determined by creating fast voltammetric techniques which are very useful. In this study, the carbon fiber electrode with high sensitivity, high $\mathrm{S} / \mathrm{N}$ ratio and increasing the mass transport is preferred due to the its good properties. In addition, this type of in-vivo measurements paves the way for the use of electrodes. Prepared carbon fiber electrode reported(Ates et al., 
2008). $4 \mathrm{~V}$ immersed in the solution containing the carbon fiber electrode potential under alylphenol for isolation(Strein and Ewing, 1992). Fc-conjugates of anti-VEGF; first FC dissolved in the buffer, after activated the NHS / EDC and treated anti-VEGF(Lim and Matsunaga, 2001). Carbon fiber electrode modification on the mapping carboxylic acid is a bifunctional linker was used(Jeffamine). The advantage of using immobilized antibodies bind to the effect of Jeffamine was more effective than other linkers(Cao et al., 2007). Immobilized antigen-antibody regulation also allows you to fine orientation. Thus, Fcderived anti-VEGF was immobilized on the electrode surface. Surface characterization was confirmed by SEM scans. Immobilizations are determined by electrochemical CV data. Stabilization of covalently immobilized on the surface of the electrode increased. Incubation time and amount of anti-VEGF are two major factors in the study. Carbon fiber electrode surface, a maximum of 50 to $750 \mathrm{pg} / \mathrm{ml}$ antibody binds to the Fc-immobilized with antiVEGF; this value rises to $800 \mathrm{pg} / \mathrm{mL}$. Lower limit of determination of VEGF $38 \mathrm{pg} / \mathrm{ml}$, respectively. The maximum value of RSD $8.9 \%$. Specificity studies of this immunosensor was carried out with IgG and did not give an important signal.

Kim et al. developed for the determination of VEGF in another study, indium tin oxide layer on the metal nanoparticles electrochemical measurement system. Recently metal nanoparticles on biosensor technology with immobilized electrodes are used widely. In this study, AuNPs / ITO electrode modified with the VEGF level was measured. AuNPs primarily prepared in accordance with the protocol developed by Kumar et al.(Kumar et al., 2008). Then attached to the surface of the electrode modified with AuNPs by APTES(Seiwert et al., 2008). ITO electrode modified with AuNPs of VEGF after treatment were immersed in a solution of BSA to prevent non-specific binding. VEGF gold nanoparticles were covalently modified with thiol groups to connect to the 2-MEA was obtained to be rendered. This is anchored on thiol groups of VEGF with sorrowful AuNPs VEGFantibodyfragment / AuNPs / APTES / ITO modified electrode formed. Fc-fragments of anti-VEGF prepared after modification is as follows: Fc condition with anti-VEGF conjugate formed through the activation of the anhydride(Kossek et al., 1996). This conjugate was prepared by applying the modified electrode surface was measured. One of the important points of the steps of immobilization induced by 2-MEA that is the process of purification of fragments. Electrochemical analysis of measurement systems used in the CV and DPV. Lower determination limit was determined as $100 \mathrm{pg} / \mathrm{mL}$. Table 5 shows voltammetric based immunosensors for PSA.

\begin{tabular}{|c|c|c|c|c|}
\hline \multicolumn{5}{|c|}{ Table Of Electrochemical Transducers For Detection Of PSA } \\
\hline $\begin{array}{c}\text { Measurement } \\
\text { Technique }\end{array}$ & Immobilization Technique & $\begin{array}{c}\text { Low } \\
\text { Detection } \\
\text { Limit }\end{array}$ & $\begin{array}{c}\text { Lineer } \\
\text { Detection } \\
\text { Limit }\end{array}$ & Reference \\
\hline Voltammetric & $\begin{array}{c}\text { Fc-derived-anti-VEGF } \\
\text { /Jeffamine/CFE }\end{array}$ & $38 \mathrm{pg} / \mathrm{mL}$ & $\begin{array}{c}50 \text { to } 750 \\
\mathrm{pg} / \mathrm{mL}\end{array}$ & $\begin{array}{c}\text { Prabhulkar } \\
\text { et al., 2009 }\end{array}$ \\
\hline Voltammetric & $\begin{array}{c}\text { AuNPs/VEGFantibodyfragment/ } \\
\text { AuNPs / APTES/TO modified } \\
\text { electrode }\end{array}$ & $\begin{array}{c}100 \\
\mathrm{pg} / \mathrm{mL}\end{array}$ & $\begin{array}{c}100 \text { to } \\
600 \mathrm{pg} / \mathrm{mL}\end{array}$ & $\begin{array}{c}\text { Kim et al., } \\
2009\end{array}$ \\
\hline
\end{tabular}

Table 5. Voltammetric Immunosensors For Detection of PSA 


\subsection{Optic transducers}

Especially in the field of optical transducers; fluorescence, inferometry, optical wave spectroscopy, and surface plasmon rezonance used in sensor systems(Tothill, 2009). Usually the light emissions of fluorescence signal to realize biocomponents, QD etc. are used to create the signaling molecules. Especially in recent days at the molecular level without need to label the SPR technology allows the immunochemical analysis. Determination was carried out in very specific, allowing real-time analysis(Keusgen, 2002, Yang et al., 2005; Vaisocherova et al., 2007). Nanocrystals are used for labeling luminescent molecules for molecular and cellular imaging(Maxwell et al., 2002; Gerion et al., 2001; Gerion et al., 2002, Kim et al., 2004).

\subsubsection{Development of the optical Immunosensors for the determination of AFP}

$\mathrm{Bi}$ et al. developed for the determination of biomarker AFP multilayer enzyme-coated ultrasensitive chemiluminescent immunoassay system. In this system, the carbon nanaotubes are used for immobilization material. Besides the high stability and luminescence properties of the surface area of carbon nanotubes in the winning offers impressive features(Sumpter et al., 2008, Shen et al., 2004; Tasis et al., 2006). The study functionalize carbon nanotubes with carboxyl groups can be treated primarily by acid, and they were now ready for immobilization(Mung et al., 2005). On the carboxyl groups formed on the MWCNT then coated with PDDA. The positively charged PDDA was immobilized on the negatively charged HRP (HRP / PDDA) $n$ / MWCNT multilayer structure of the enzyme were continued several times in this study by creating layered system formed. HRP immobilized on the PDDA-MWCNT after the negatively charged PSS adsrobe on this structure on the then secondary AFP antibodies were added and MWCNT-(PDDA / HRP) $4^{-}$ $\mathrm{PDDA} / \mathrm{PSS}-\mathrm{Ab}_{2}$ modification prepared. MBs with the primary antibody conjugated with the method have been developed by the Imato and colleagues (Zhang et al., 2007a, b). LBL films as a result of sandwich type immuno complex, depending on the enzyme activity by measuring the permeability values of the system. In this system, the amount of $1 \mathrm{ng} / \mathrm{mL}$ was determined at the level of AFP. AFP linear measurement is between 0.02 to $2 \mathrm{ng} / \mathrm{ml}$. A successful realization of the system as a result of the signal by increasing the light interaction with the CNT-LBL bio pointer by measuring the high sensitivity, good accuracy and operational stability as a result offers the possibility to analyze very large amounts.

\subsubsection{Immunosensors based SPR for detection of CRP}

$\mathrm{CRP}$, a biomarker, is very well known. As mentioned in previous sections of early diagnosis is extremely important. Meyer et al. developed to allow different samples to be analyzed in combination with SPR sensor technology. SPR is an optical instrument and proteins, binding of antigen and antibodies used in monitoring processes. The biggest advantage of up to eight analyte by a measurement provides for a shorter time(Meyer et al., 2006). In this study, the biotin-coated gold electrodes used with a layer of APTES(Davidson et al., 2004; Phadtare et al, 2004; Yakovleva et al., 2003), thus creating an amino surface with biotin-NHS match ends formed. On this layer and biotinylated streptavidin antibody(Milka et al., 2000) on the application of CRP measurement was carried out by applying the secondary antibody. $\mathrm{K}_{\mathrm{dis}}$ antigen-antibody method, the values can be determined easily. For this purpose, Edwards and Leatherbarrow method(1997) was used. BSA is used to prevent non-specific binding of the system. Whether the application shows a significant increase in signal for $1 \mu \mathrm{g} / \mathrm{mL}$ 
example. In this case, the signal has been more than 4 times the noise and the lower limit of determination. Dynamic and linear measuring range $2 \mathrm{mg} / \mathrm{ml}$ to $5 \mathrm{mg} / \mathrm{mL}$ were determined. SPR sensor was developed in two different CRP antibody (C2 and C6) have the possibility of measurement separately. SPR sensor, two different epitope of these two biomolecule identification of features of the high specificity can be determined. Designed using the most important feature of the SPR biosensor is that has no limitations, such as ELISA, sample color, origin, or allow the possibility of measurement can yield without affecting the matrix.

\subsubsection{SPR based biosensors developed for determination of CEA}

Ladd et al. developed SPR-based measurement system for direct determination of CEA. As is known in real-time SPR, and do not need to label the quantitative determination of biomolecules is a measurement technique that allows each opportunity. Cancer diagnosis is very important in the early diagnosis offers the possibility to analyze. In this study the clone ovarian cancer in terms of levels of anti-CEA levels were used to determine by SPR sensor. In order to verify the measurement system, the data obtained from samples were confirmed by ELISA. The sensor is based on the measurement of total reflectance method(Boozer et al., 2004, Ladd et al., 2004). Polychromatic light source, optical prism reflecting light rays emitted from a thin metal layer after the reflected rays fall on the four independently collected by the spectrophotometer so that allows you to create 4 different measurement channels. In this study, $2 \mathrm{~nm}$ thick $\mathrm{Cr}$ and $55 \mathrm{~nm}$ thick gold electrode surface is covered electron beam evaporation. After cleaning the electrode surface with UV $\mathrm{COOH}$ oligoetilenglikol: PGP solution is created with the SAM. Functionalized with COOH groups on the SAM layer, activated NHS / EDC and proteins were immobilized. After this process was the determination of CEA antibody in serum samples were applied to the electrode surface by the flow system. In the second sample solution containing the secondary antibodies anti-human IgG-HRP conjugate was applied. Compared with the ELISA method for direct analysis of the SPR signal of study of molecules has a higher response. ELISA and SPR studies that there are two different cases of non-specific binding Ladd et al. determinism which causes the application of surface chemistry and the sample. Surface modification and protein immobilization of the SPR and ELISA is shown by the many differences. SPR analysis of CEA as a result the basic purpose of this study consisted of developing immunosensor and ELISA tests for confirmation of the results of CEA was measured directly.

\subsubsection{SPR based biosensors developed for determination of HER-2}

Gohring et al. developed very different system for the determination of HER-2 for the diagnosis of breast cancer, opto-fluidic biosensor system using the ring resonator. As is known, the most common cancer among women is breast cancer, only 200,000 women in the USA affected by breast cancer(Cheng et al., 2009; Lippman, 2008; Jemal et al., 2006). The early diagnosis of cancer in recent years to study protein basis biomarkers the most widely used on the issue(Kearney and Murray, 2008; Gullick, 2001). Excessive secretion of growth factor receptor in human epidermis occurs during breast cancer. HER-2 levels in healthy people are between 2 to $15 \mathrm{ng} / \mathrm{mL}$, sick people are between the 15 to $75 \mathrm{ng} / \mathrm{mL}$ (Capobianco et al, 2008). For this reason, the quantitative detection of biomarkers need to be fast and responsive. Ring resonator was used for analysis in this study, thin high-Q ring resonator on 
microfluidic system used to support the capillary walls. In this experiment by heating the desired radius under OFRRs silica glass door until it pulled carbon dioxide laser has been extended to increase the sensitivity of HF were treated with less than $3 \mu \mathrm{m}$ around to $5 \mu \mathrm{m}$ thickness were produced(White and Oveys, 2006, Zhu et al., 2008, White et al ., 2008). Interact with light in a fiber ring connecting the cable OFRR resonance, known as whispering gallery mode(WGM) creates. $1550 \mathrm{~nm}$ laser diode used in this experiment can be adjusted in length (Fig. 3).

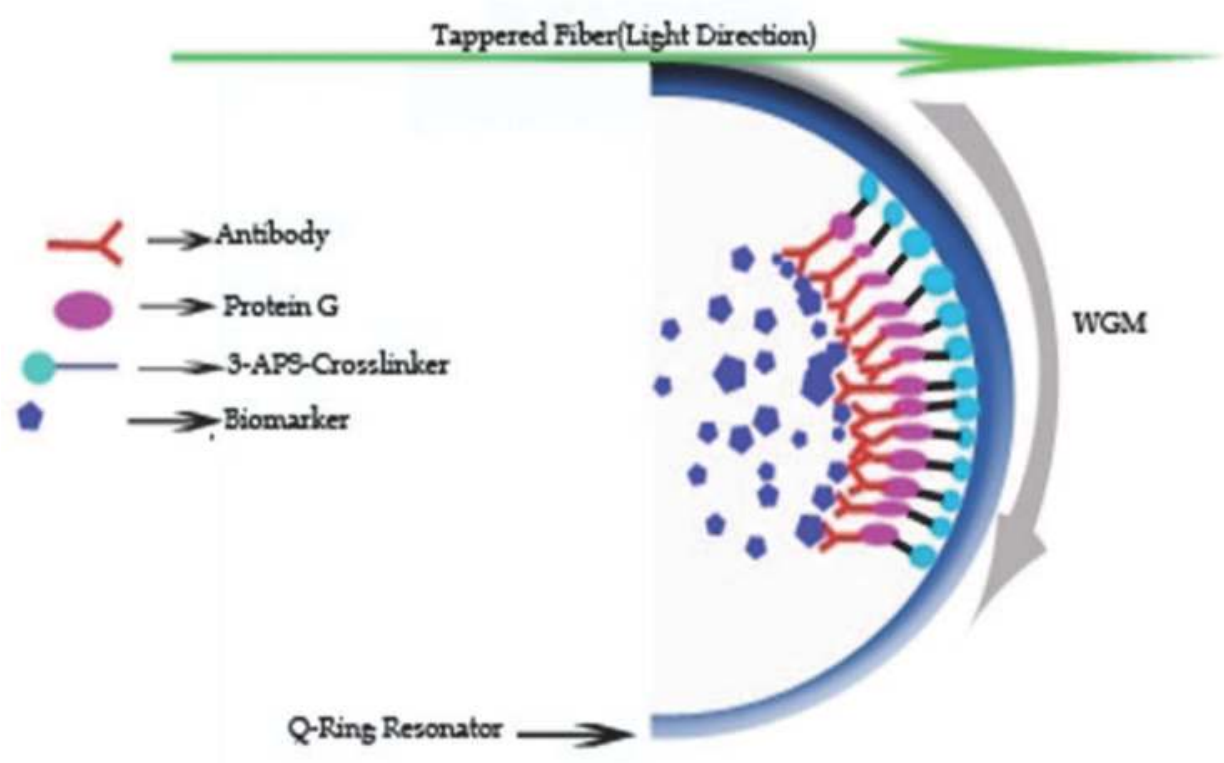

Fig. 3. A schematic representation of AFP sensing by a microfluidic immunosensor system

Nanometer size of measurement unit as a measure of sensitivity to OFRR each diffraction measurement of the index unit (RUI). OFRR inner surface (Fig. 3) the preparation should be modified to show the great sensitivity with small concentrations. First of all HF from the surface through the surface will be loaded. Then, the surface layer of 3-APS is obtained by passing an aminosilan. After passing through the DMP, then the creation of a layer of crosslinking of recombinant protein $\mathrm{G}$ immobilized on aminosilan surface, immobilization of this protein, the $G$ antibodies provided orientation. In order to prevent non-specific binding, casein was used in blocking agent. HER2 biomarker 13, 16, 20, 25, 33, 50, 75, 100 and $250 \mathrm{ng}$ / $\mathrm{ml}$, all experiments were completed in 30 minutes, the ring was cleaned after each use with the HF. Casein-bound or loosely linked with HER2 after treatment with antibodies were to remove the casein solution from the system. This is a specially designed syringe pump is used for transactions. Lower determination of limit is $10 \mathrm{ng} / \mathrm{mL}$. $0.3 \mathrm{pm}$ is observed as a negative shift of the shift measurements, the sample is applied, showed that $4.5 \mathrm{pm}$ shift. The only disadvantage of the system haven't been found better biomolecule to prevent non-specific binding of system. Conclusion Gohring et al. by responding to the rapid, sensitive and reproducible system was developed quickly. 


\subsection{Piezoelectric transducers}

Hereinafter piezoelectric quartz crystals to provide mass to hear the transducers unlabeled measurements and the electrode on the surface of the gold-coated sensors are designed using the small mass changes depending on the measurement of change are based on the crystal resonance differences(Sullivan and Guilbault, 1999). Label was using a variety of recently developed systems for QCM immunosensors(Kurosawa et al., 2004, McBride and Cooper, 2008). QCM sensors, the biggest disadvantage of solution matrix applied to any kind of analyte.

\subsubsection{QCM based biosensors developed for determination of CRP}

Kim et al. QCM-based indirect competitive immunosensor systems developed for the determination of CRP. In this system, an indirect competitive QCM immunosensor system (IC) as the startup process as a monoclonal anti-CRP antibody was immobilized and was measured in serum biomarkers. Transducer in the system for measuring the surface has been prepared according to the method developed by Park and Kim (Park and Kim, 1998). QCM surface was treated separately, first sodym hydroxide and hydrochloric acid. The sensor surface is covered with sulfo-LC-SPDP is prepared for immobilization of antigen to be taken as a result of previous studies that suggested the best sensitivity (Park and Kim, 1998). Mixed with sulfo-LC-SPDP dithioeritrol CRA and CRP reacted with the latest sensor QCM gold electrode surface was prepared by treatment. High ionic strength was chosen to minimize the false positive signal and time of CRP measurement(Kim et al., 2004). In this study, a relatively high concentration of immobilized antigen-antibody binding and measurement is good. After that, the sensor response to an antigen-antibody interaction is between 0010 to $0.5 \mathrm{mg} / \mathrm{mL}$ antibody concentration was determined. Specificity studies with BSA bind to the surface of the sensor, almost no binding was observed with BSA. 0,130 to 25,016 , depending on the time sensitivity of the sensor were examined $\mathrm{ng} / \mathrm{mL}$, in a linear range to be determined. IC, according to the response of the sensor decreases with increasing concentration of CRP (Hamalek et al., 2002; Adanyi et al., 2007). Prepared by the same enzyme system in the $0.3 \mathrm{ng} / \mathrm{mL}$ lower limit determined in this study, moreover, a close $87 \mathrm{fM}$ validation coefficient was calculated as 0.9893 .

Kim et al. Immunosensors QCM gold nanoparticle-based systems have developed that increase the signal. In this study with the help of AuNPs the signal was amplified significantly. Streptavidin-coated gold nanoparticlws complexation of antigen antibody was measured by the IC assay format. Anti-CRP buffer by dissolving into the sulpho-NHS-LCbiotin was carried out by adding antibodies. QCM surface, hydro-chloric acid and sodium hydroxide in a separate location after being treated with sulpho-LC-SPDP to conjugate CEA was created by mixing the solution after the mixture was incubated with dithioeritrol tihol groups that hosts on the conjugated CRP, QCM was immobilized on the drops. Established a system of micro-flow system with the help of dispersing peristalsis sample pump is smart. At this point the resonance frequency was obtained from stationary phase. After a series of solution containing biotinylated that anti-CRP applied to $0.1 \mathrm{pM}$ between $0.53 \mathrm{nM}$. According to the obtained resonance shift and bonded CRP measurement was carried out by the changes resulting from the resonance shift observed. In this study, performance of immunosensor is increased with the implementation of the nanomaterials. As for the sensitivity of the system on chip, $2 \mathrm{mg} / \mathrm{mL}$ antigen coated, biotinilated and competitive reaction between the free $\mathrm{CRP}$, decreased concentration brings increased differentiation frequency (Halamek et al., 2002). Accordingly, the relative rate of antibody binding 
decreases. These values indicate that antibodies bound on AuNPs attached with a mass deposition. According to the data being compared with the control value obtained by adding the shift $1 \mathrm{pm}$ shift control measurement of CRP is less than that observed. Based on this data to determine the lower limit is determined as $0.1 \mathrm{pM}$. AuNPs on the surface have increased the sensitivity of the sensor. This method is more sensitive compared with other measurement methods based on related data have shown that (Meyer et al., 2002, Meyer et al., 2007; Vikholm-Lundin et al., 2006). 87fM be determined until this study, low-range signal. Verification of the system is determined as coefficient of 0.9796 . Thus, the use of modified antibodies with increased sensitivity of the IC immunosensor QCM decreased to low levels of CRP measurement limits. Table 6 summarizes immunosensors based QCM for CRP detection.

\begin{tabular}{|c|c|c|c|c|}
\hline \multicolumn{7}{|c|}{ Table Of QCM Transducers For Detection Of CRP } \\
\hline $\begin{array}{c}\text { Measurement } \\
\text { Technique }\end{array}$ & Immobilization Technique & $\begin{array}{c}\text { Low } \\
\text { Detection } \\
\text { Limit }\end{array}$ & $\begin{array}{c}\text { Lineer } \\
\text { Detection } \\
\text { Limit }\end{array}$ & Reference \\
\hline QCM & CRP/DTHE/sulfo-LC- & $\begin{array}{c}0.3 \mathrm{ng} / \mathrm{mL} \\
(87 \mathrm{fM})\end{array}$ & $\begin{array}{c}0010 \text { to } 0.5 \\
\mathrm{mg} / \mathrm{mL}\end{array}$ & $\begin{array}{c}\text { Kim et al., } \\
2010\end{array}$ \\
\hline QCM & $\begin{array}{c}\text { Anti-CRP/sulpho-NHS-LC- } \\
\text { biotin/QCM }\end{array}$ & $\begin{array}{c}2 \mathrm{mg} / \mathrm{mL} \\
(0.1 \mathrm{pM})\end{array}$ & $\begin{array}{c}0.1 \mathrm{pM} \text { to } \\
0.53 \mathrm{nM}\end{array}$ & $\begin{array}{c}\text { Kim et al., } \\
2009\end{array}$ \\
\hline
\end{tabular}

Table 6. QCM Immunosensor For Detection Limits Of CRP

\subsubsection{QCM based biosensors developed for determination of PSA}

Another study using the QCM Immunosensors Uludağ and Tothill developed an immunosensor based on the measurement of the amount of PSA using nanoparticles in human serum $(75 \%)$. As is well known that is important early diagnosis of cancer which death rate among men with prostate cancer is known to be high, and confirmed by the WHO datas(Panini et al., 2008). In this study, a simple and rapid determination of the PSA is designed to carry out the QCM biosensor. As is well known among the QCM contains two electrode in a couple of thin layers of quartz (wafer). Mass loss or a mass connected to the surface by measuring the change in frequency allows the analysis. Although the analyte solution, the viscosity of the system are affected in the determination of the serum samples were carried out on the biomarker in this study. To minimize the matrix effect; the detergent, salt and other substances were used to measure the PSA and PSA-ACT complex. First, gold nanoparticles formed, were treated with anti-PSA conjugate. After the QCM gold disc for the purpose of the creation of a MUA SAM layer is covered with all night long. After NHS / EDC activation with anti-PSA and on the SAM-coated chip for controlling the flow rate used in the IgG molecule $80 \mu \mathrm{l} / \mathrm{min}$ to be applied. Connecting to BSA and ethanolamine were used to block the non-active carboxyl groups. Frequency measurement was carried out in two minutes after the injection of proteins. PSA complex in serum is in conjunction with the ACT. This is a combination of two molecules by the presence of total PSA (tPSA) can be quantified. In this study, accurate measurement of this complex due to the mixing ratio of 1:1 was used PSA and PSA-ACT complex. After this process of IgG binding to the anti-PSA and then to 380 and $520 \mathrm{~Hz}$ frequency change of the order have 
been observed. BSA surface with no frequency change is observed during the application of surface blocked were good in terms of measurement. PSA is given to the method of Sandwich, first applied to the surface of the electrode only sample of anti-PSA in $5 \mathrm{~Hz}$ frequency change was recorded accordingly. Linear measurement range of the experiments with PSA 2.3 to $150 \mathrm{ng} / \mathrm{mL}$ was determined. With this method, sandwich method to determine, direct determination limit is more sensitive 4 times. As is well known for quartz disk viscosity is affected when applied to the buffer and serum samples showed different results. Sample is applied to determine the lower limit of $10 \%$ serum containing $10.2 \mathrm{ng} / \mathrm{ml}$ to $18.1 \mathrm{ng} / \mathrm{ml}$. Non-specific binding of carboxymethyl dextran is used to prevent nonspecific binding of the surface decreased by $88 \%$ (Choi et al., 2006, Yin et al., 2005). In this study, experiments in human serum with $75 \%$ diluation as a result of the realization of the measurement process as a linear $150 \mathrm{ng} / \mathrm{mL}$ hesaplanmi $100 \%$ to determine the serum ratio of $0: 29$ was determined as the $0.39 \mathrm{ng} / \mathrm{mL}$. In this study, the rate of change in the measurement of serum with additives will be examined and analyzed by $98 \%$ of nonspecific binding of different additives were crossed in front.

\section{Conclusion}

It is vitally important to diagnose cancer early for treatment patients succesfully. Consequently there will always be a need to develop more sensitive, economical, and simple diagnostic biosensors because new cancer biomarkers are discovered continuously. Biosensors have the potentiality to diagnose cancer sensitively, simply, and economically. Unfortunatelly the biosensor based measurement systems need to be further developed to use these devices in analyzing of many cancer biomarkers simultaneously. Consequently, as a future prospestive, biosensor technology should gear to adapt these systems for multi target analysis by the help of microfluidics technologies. Beside using of the newly discovered nanomaterials in the development of biosensors can increase the sensitivity and selectivity of these devices.

\section{References}

Achim, C.; Shi, H.; Yeh, J.I. (2009) March 5. Biosensors and related methods. United States patent application US 2009/0061451.

Adányi, N.; Levkovets, I.A.; Rodriguez-Gil, S.; Ronald, A.; Váradi, M.; Szendro I. (2007) Development of immunosensor based on OWLS technique for determining Aflatoxin B1 and Ochratoxin A, Biosens. Bioelectron. 22, 797-802.

Aleiner, I.L.; Efetov, K.B.; (2006) Effect of Disorder on Transport in Graphene, Physical Review Letters 97:2323, 236801, American Physical Society, 12.

Andrey, L.G.; Plamen, A.; Michael, W.; Ebtisam, W.; (1998). Immunosensor: electrochemical sensing and other engineering approaches. Biosens. Bioelectron. 13, 113.

Antosiewicz, J. (1995). Computation of the dipole moments of proteins ,Biophysical Journal, $69,4,1344-1354$

Armstrong, F.A.; (2005) Recent developments in dynamic electrochemical studies of adsorbed enzymes and their active sites, Current Opinion in Chemical Biology, 9, $2,110-117$ 
Ates, M.; Sarac, A.; Sezai; Wolfgang S.; (2008) Carbon fiber microelectrodes electrocoated with polycarbazole and poly(carbazole-co-p-tolylsulfonyl pyrrole) films for the detection of dopamine in presence of ascorbic acid, 160, 1-2, pp.247 251.

Augustin, H.G.; Koh, G.Y.; Thurston, G.; Alitalo. (2009) Control of vascular morphogenesis and homeostasis through the angiopoietin-Tie system. Nat Rev Mol Cell Biol 10:165-77. B. Haghighi, S. Varma, F.M.Alizadeh,Y. Yigzaw, L. Gorton, Prussian bluemodified glassy carbon electrodes-study on operational stability and its application as a sucrose biosensor, Talanta 64 pp. 3-12.

Babya, T.T.; Aravinda, S.S.J.; Arockiadossa, T.; Rakhia, R.B.; Ramaprabhu, S. (2010). Metal decorated graphene nanosheets as immobilization matrix for amperometric glucose biosensor, Sens. Actuators B: Chem. 145 71-77.

Bain, C.D.; Troughton, E.B.; Tao, Y.T.; Evall, J.; Whitesides, G.M.; Nuzzo, R.G.; (1989). Formation of monolayer films by the spontaneous assembly of organic thiols from solution onto gold, Journal of the American Chemical Society, 111,321-335.,

Barbora, M.; Samuele, T.; Marcus, T.; Karl, G.; Stefan, Z. (2010). "Poly(ethylene glycol) Adlayers Immobilized to Metal Oxide Substrates Through Catechol Derivatives: Influence of Assembly Conditions on Formation and Stability"., Langmuir, 26 (6), 4018-4026.

Bartsch, R.A.; Maeda, M. (1998) Molecular and Ionic Recognition with Imprinted Polymers, American Chemical Society, Washington, DC.

Baschong, W; Stierhof, Y.D. (1998) Preparation, use, and enlargement of ultrasmall gold particles in immunoelectron microscopy. Microsc Res Tech. 42:66-79.

Bauer, C.G.; Eremenko, A.V.; Ehrentreich-Forster, E.; Bier, F.F.; Makower, A.; Halsall, H.B.; Heineman, W.R.; Scheller, F.W. (1996). Zeptomole-detecting biosensor for alkaline phosphatase in an electrochemical immunoassay for 2,4- dichlorophenoxyacetic acid, Anal. Chem., 68, 2453-2458.

Belinsky, S.A. (2004) Gene-promoter hypermethylation as a biomarker in lung cancer. Cancer ; 4,1-11

Benchimol, S.; Fuks, A.; Jothy, S.; Beauchemin, N.; Shirota, K.; Stanners, C.P. (1989). Carcinoembryonic antigen, a human tumor marker, functions as an intercellular adhesion molecule Cell, 57, 2, 327-334

Benson, M.C.; Whang, I.S.; Olsson, C.A.; Mcmahon, D.J.; Cooner, W.H. (1992). The use of PSA density to enhance the predictive value of intermediate levels of serum PSA. Journal Of Urology 147, 817-821.

Bi, S.; Zhou, H.; Zhang, S.S. (2009). Multilayers enzyme-coated carbon nanotubes as biolabel for ultrasensitive chemiluminescence immunoassay of cancer biomarker, Biosens. Bioelectron. 24, 2961-2966.

Bienvenue, J.M.; Duncalf, N.; Marchiarullo, D.; Ferrance, J.P.; Landers, J.P. (2006). Microchip-based cell lysis and DNA extraction from sperm cells for application to forensic analysis. J. Forensic Sci. 51, 266-273.

Boehm, M.K.; Mayans, M.O.; Thornton, J.D.; Begent, R.H.J.; Keep, P.A.; Perkins, S.J. (1996). Extended glycoprotein structure of the seven domains in human carcinoembryonic antigen by X-ray and neutron solution scattering and an automated curve fitting 
procedure: implications for cellular adhesion, Journal of Molecular Biology. 259, 718-736.

Boozer, C.; Ladd, J.; Chen, S.F.; Yu, Q.; Homola, J.; Jiang, S.Y. (2004) DNA directed protein immobilization on mixed ssDNA/oligo(ethylene glycol) self-assembled monolayers for sensitive biosensors, Analytical Chemistry, 76, 6967-6972.

Bradford, T.J.; Tomlins, S.A.;Wang, X.J.(2006). Chinnaiyan, A.M., Molecular markers of prostate cancer. Urol. Oncol-Semin. Ori. Inves., 24, 538-551.

Brawer, M.K., (1999). Prostate-specific antigen: current status. CA Cancer J. Clin., 49, 264281.

Brayer, G.D.; Luo, Y.G.; Withers, S.G. (1995). The structure of human pancreatic alphaamylase at 1.8 angstrom resolution and comparisons with related enzymes, Protein Science, 4, 1730-1742.

Capobianco, J.A.; Shih, W.Y.; Yuan, Q.; Adams, G.P.; Shih, W. (2008). Label-free, allelectrical, in situ human epidermal growth receptor 2 detection, Rev. Sci. Instrum., 79, 076101.

Carrara, S.; Bhalla, V.; Stagni, C.; Benini, L.; Ferretti, A.; Valle, F.; Gallotta, A.; Ricco, B.; Samori, B.; (2009). Sens. Actuator B: Chem., 136 (1), 163-172.

Celestino, P.; Grubelnik, A.; Tiefenauer, L. (2000). Ferrocene-avidin conjugates for bioelectrochemical applications., Biosensors \& Bioelectronics, 15, 431-438

Cello, J.; Paul, A.V.; Wimmer, E. (2002) Chemical synthesis of poliovirus cDNA: generation of infectious virus in the absence of natural template, Science, 297, 1016-1018.

César Fernández-Sánchez, Ana M. Gallardo-Soto, Keith Rawson, Olle Nilsson and Calum J. McNeil. Quantitative impedimetric immunosensor for free and total prostate specific antigen based on a lateral flow assay format., Electrochemistry Communications, Volume 6, Issue 2, February 2004, Pages 138-143

Cheng, H. D.; Shan, J.; Ju, W.; Guo, Y.; Zhang, L. (2009) Automated breast cancer detection and classification using ultrasound images: a survey, Pattern Recogn., 43, 299-317.

Cheng, H.D.; Shan, J.; Ju, W.; Guo, Y.; Zhang, L. (2009) Automated breast cancer detection and classification using ultrasound images: a survey, Pattern Recogn., 43, 299-317.

Cheng, L.; Pacey, G.E.; Cox, J.A.; (2001). Carbon electrodes modified with ruthenium metallodendrimer multilayers for the mediated oxidation of methionine and insulin at physiological Ph. Anal. Chem., 73, 5607-5610.

Chikkaveeraiah, B.V.; Bhaskara, V.C.; Bhirde, A.; Malhotra, R.; Patel, V.; Gutkind, J.S.; Bhirde, A.; Malhotra, R.; Patel, V.; Gutkind, J.S. and Rusling, J.F. (2009) Single-wall carbon nanotube forest arrays for immunoelectrochemical measurement of four protein biomarkers for prostate cancer, Anal Chem, 81: 9129-9134.

Choi, J.W.; Kang, D.; Jang, Y.H.; Kim, H.H.; Min, J.; Oh, B.K. (2008) Ultra-sensitive surface plasmon resonance based immunosensor for prostate-specific antigen using gold nanoparticle-antibody complex., Colloids and Surfaces A: Physicochemical and Engineering Aspects, 313-314, 655-659.

Choi, J.W.; Kim, Y.K.; Kim, H.J.; Lee, W.; Seong, G.H. (2006) Lab on a Chip for monitoring the quality of raw milk, J. Microbiol. Biotechnol., 16, 1229-1235.

Choi, J.-W.; Oh, K.W.; Thomas, J. H.; Heineman, W. R.; Halsall, H. B.; Nevin, J. H.; Helmicki, Henderson H. T. and Ahn C. H., (2002) "An integrated microfluidic biochemical 
detection system for protein analysis with magnetic bead-based sampling capabilities," Lab Chip, 2, 27-30, (5.821).

Corso, C.D.; Stubbs, D.D.; Lee, S.; Goggins, M.; Hruban, R.; Hunt, W.D. (2006) Real-time detection of mesothelin in pancreatic cancer cell line supernatant using an acoustic wave immunosensor Cancer Detection and Prevention, 30, 180-187.

Cram, D.J. (1988). The design of molecular hosts, guests, and their complexes (Nobel lecture), Angewandte Chemie-International Edition in English, 27, 1009-1020.

Dai, Z.; Yan, F.; Yu, H.; Hu, X.; Ju, H. (2004). Novel amperometric immunosensor for rapid separation-free immunoassay of carcinoembryonic antigen. Journal of Immunological Methods, 287, 1-2, 13-20.

Darain, F.; Park, D.-S.; Park, J.-S.; Chang, S.-C.; Shim, Y.-B. (2005).A separation-free amperometric immunosensor for vitellogenin based on screen-printed carbon arrays modified with a conductive polymer Biosens. Bioelectron, 20, 1780-1787

Davidsson, R.; Genin, F.; Bengtsson, M.; Laurell, T.; Emneus, J.; (2004). Microfluidic biosensing systems. Part I. Development and optimisation of enzymatic chemiluminescent micro-biosensors based on silicon microchips. Lab Chip 5, 481487.

de Vasconcelos, E.A.; Peres, N.G.; Pereira, C.O.; da Silva, V.L.; da Silva, E.F. Jr.; Dutra, R.F. (2009) Potential of a simplified measurement scheme and device structure for a low cost label-free point-of-care capacitive biosensor. Biosens Bioelectron.,25, 4, 870-6

Downard, A.J.; Mohamed, A.B.; (1999). Suppression of protein adsorption at glassy carbon electrodes covalently modified with tetraethylene glycol diamine. Electroanalysis $11,418-423$.

Du, D.; Zou, Z.X.; Shin, Y.S.; Wang, J.; Wu, H.; Engelhard, M.H.; Liu, J.; Aksay, I.A.; Lin, Y.H. (2010). "Sensitive Immunosensor for Cancer Biomarker Based on Dual Signal Amplification Strategy of Graphene Sheets and Multienzyme Functionalized Carbon Nanospheres," Anal. Chem. 82, 2989-2995

Duffy, M.J. (2001). Carcinoembryonic antigen as a marker for colorectal cancer: is it clinically useful, Clinical Chemistry 47, 624-630.

Dumitrescu, I.; Unwin, P.; MacPherson, J. (2009) Electrochemistry at carbon nanotubes: perspective and issues, Chem. Commun., 45, 6886-6901.

Edwards, P.R.; Leatherbarrow, R.J.; (1997). Determination of association rate constants by an optical biosensor using initial rate analysis. Anal. Biochem. 246, 1-6.

Ferrara, N.; Davis-Smyth, T. (1997).The biology of vascular endothelial growth factor. Endocr. Rev. 18, 4-25.

Fiorito, P.A.; Gonzales, V.R.; Ponzio, E.A.; Torresi, S.I.C.D. (2005). Synthesis, characterization and immobilization of Prussian blue nanoparticles. A potential tool for biosensing devices., Chem. Commun. 3, 366.

Forrest, S.R. (1997). Ultrathin organic films grown by organic molecular beam deposition and related techniques, Chem. Rev. 97,1793-1896.

Frens, G.; (1973) Controlled nucleation for the regulation of the particle size in monodisperse gold suspensions. Nat Phys Sci;241:20-2. 
Gao, Q.; Ma, Y.; Cheng, Z.; Wang, W.; Yang, X. (2003). Flow injection electrochemical enzyme immunoassay based on the use of an immunoelectrode strip integrate immunosorbent layer and a screen-printed carbon electrode., Analytica Chimica Acta, 488, 1, 61-70.

Geim, A.K.; Novoselov, K.S. (2007) The rise of graphene . Nat. Mater. 6, 183-191.

Georganopoulou, D.G.; Chang, L.; Nam J.M.; Thaxton, C.S.; Mufson, E.J. (2005) Nanoparticle-based detection in cerebral spinal fluid of a soluble pathogenic biomarker for Alzheimer`s disease, Proc. Natl. Acad. Sci. USA 102,2273-2276.

Gohring, J.T.; Dale, P.S.; Fan, X (2010= Detection of HER2 breast cancer biomarker using the opto-fluidic ring resonator biosensor.,Sensors and Actuators B: Chemical, 146, 1, 226-230.

Goldenberg, D.M.; Sharkey, R.M.; Primus, F.J. (1976). Carcinoembryonic antigen in histopathology: immunoperoxidase staining of conventional tissue sections. J. Natl. Cancer Inst. 57, 11-22.

Grabar, K.C.; Freeman, R.G.; Hommer, M.B.; Natan, M.J. (1995). Preparation and Characterization of Au Colloid Monolayers,Analytical Chemistry , 67, 4, 735-43.

Gullick, W.J. (2001). Update on HER-2 as a target for cancer therapy: alternative strategies for targeting the epidermal growth factor system in cancer. Breast Cancer Res. 3, 390-394.

Gustafsson, J.B.; Moons, E.; Widstrand, S.M.; Johansson, L.S.O. (2006). Growth and

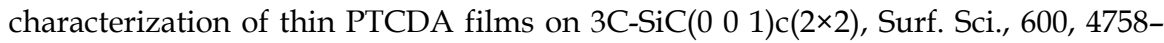
4764 .

Halámek, J.; Makower, A.; Skládal, P.; Scheller, F.W. (2002). Highly sensitive detection of cocaine using piezoelectric immunosensor, Biosens. Bioelectron., 17, 1045-1050.

Hansen, J. A.; Wang, J.; Kawde, A.-N.; Xiang, Y.; Gothelf, K. V.; Collins, G. (2006) QuantumDot/Aptamer-Based Ultrasensitive Multi-Analyte Electrochemical Biosensor. J. Am. Chem. Soc., 128, 2228-2229

Haupt,K. (2003), Imprinted polymers - tailor-made mimics of antibodies and receptors. Chemical Communications, 2, 171-178.

He, X.; Yuan, R.; Chai, Y.; Shi, Y. (2008). A sensitive amperometric immunosensor for carcinoembryonic antigen detection with porous nanogold film and nano$\mathrm{Au} /$ chitosan composite as immobilization matrix. Journal of Biochemical and Biophysical Methods, 70, 6, 823-829.

Heighway, J.; Kmapp, T.; Boyce, L.; Brennand, S.; (2002). Field J.K., Betticher D.C., Ratschiller D., Gugger M., Donovan M., Lasek, A. and Rickert P. Expression profiling of primary non-small cell lung cancer for target identification Oncogene 21, 7749-7763.

Hiep, H.; Kerman, K.; Endo, T.; Saito, M.; Tamiya, E. (2010) Nanostructured biochip for label-free and real-time optical detection of polymerase chain reaction, Anal. Chim. Acta, 661,111-116.

Hiep, H.M.; Yashikawa, H.; Tamiya, E. (2010). Interference localized surface plasmon resonance nanosensor tailored for the detection of specific biomolecular interactions, Anal. Chem., 82, 1221-1227. 
Hirsch, F. R.; Franklin, W. A.; Gazdar, A. F. and Bunn, P. A. Jr. (2001). Early detection of lung cancer: clinical perspectives of recent advances in biology and radiology. Clin Cancer Res,7: 5-22.

Hnaiein, M.; Hassen, W.; Abdelgani, A.; Fournier-Wirth, C.; Coste, J.; Bessueille, F.; Leonard, D.jJaffrezic-Renault, N. (2008). A conductometric immunosensor based on functionalized magnetite nanoparticles for E. coli detection, Electrochem. Commun. 10, 1152-1154.

Hook, F.; Rodahl, M.; Kasemo, B.; Brzezinski, P. (1998). Structural changes in hemoglobin during adsorption to solid surfaces: effects of $\mathrm{pH}$, ionic strength, and ligand binding, Proceedings of the National Academy of Sciences of the United States of America, 95, 12271-12276.

Hu, W.P.; Hsu, H.Y.; Chiou, A.; Tseng, K.Y.; Lin, H.Y.; Chang, G.L.; Chen, S.J. (2006). Immunodetection of pentamer and modified C-reactive protein using surface plasmon resonance biosensing. Biosens. Bioelectron. 21, 631-1637.

Huang, K.J.; Niu, D.J.; Xie, W.Z.; Wang, W. (2010). A disposable electrochemical immunosensor for carcinoembryonic antigen based on nano-Au/multi-walled carbon nanotubes-chitosans nanocomposite film modified glassy carbon electrode., Analytica Chimica Acta, 659, 1-2, 102-108.

Huhtinen, P.; Soukka, T.; Lövgren, T.; Härmä, H. (2004) Immunoassay of total prostatespecific antigen using europium(III) nanoparticle labels and streptavidin-biotin technology., Journal of Immunological Methods, 294, 1-2, 111-122.

Itoh, Y.; Ichihara, K.; (2001). Standardization of immunoassay for CRM-related proteins in Japan: from evaluating CRM 470 to setting reference intervals. Clin. Chem. Lab. Med. 39, 1154.

Jacobs, C.B.; Peairs, M.J.; Venton, B.V; (2010). Review: Carbon nanotube based electrochemical sensors for biomolecules. Analytica Chimica Acta, 662, 2, 105-127.

Jain, K.K. (2005) Nanotechnology in clinical laboratory diagnostics., Clinica Chimica Acta, $358,1-2,37-54$.

Janata, J. (1975). Immunoelectrode, Journal of the American Chemical Society, 97,2914-2916.

Jemal, A.; Siegel, R.; Ward, E.; Murray, T.; Xu, J.; Smigal, C.; Thun, M.J.; (2006) Cancer Statistics, CA Cancer J. Clin. 56 (2006) pp. 106-130.

Jemal, R.; Siegel, E.; Ward, T.; Murray, J.; Xu, C.; Smigal, M.J.; Thun, (2006) Cancer Statistics 2006, CA Cancer J. Clin. 56, 106-130.

Jensen, G.C.; Yu, X.; Munge, B.; Bhirde, A.; Gong, J.D.; Kim, S.N.; Papadimitrakopoulos, F.; Rusling, J.F. (2008). Characterization of multienzyme-antibody-carbon nanotube bioconjugates for immunosensors, J. Nanosci. Nanotechnol., 8, 1-7.

Jin, Y.; Jang, J.W.; Han, C.H.; Lee, M.H.; (2005) Development of ELISA and immunochromatographic assay for the detection of gentamicin. J. Agric. Food Chem. 53, 7639-7643.

Katz, E.; Willner, I. (2004). Integrated nanoparticle-biomolecule hybrid systems: Synthesis, properties and applications., Angew. Chem. Int. Ed., 43, 6042-6108.

Kauffman, C.A.; Malani, A.N.; Easley, C.; Kirkpatrick, P. (2007). The rise of graphee, Nat. Mater., 6, 183-191. 
Kaufman, E.D.; Belyea, J.; Johnson, M.C.; Nicholson, Z.M.; Ricks, J.L.; Shah, P.K.; Bayless, M.; Pettersson, T.; Feldoto, Z.; Blomberg, E.; Claesson, P.; Franzen, S. (2007). Probing protein adsorption onto mercaptoundecanoic acid stabilized gold nanoparticles and surfaces by quartz crystal microbalance and zeta-potential measurements, Langmuir, 23, 6053-6062.

Kearney, A.J.; Murray, M.; (2008). Breast cancer screening recommendations: is mammography the only answer? J. Midwife. Women Health 54 pp. 393-400.

Kim, D.M.; Noh, H.; Park, D.S.; Ryu, S.H.; Koo, J.S.; Shim, Y. (2009). Immunosensors for detection of Annexin II and MUC5AC for early diagnosis of lung cancer., Biosensors and Bioelectronics, 25, 2, 456-462

Kim, G.; Kim, K.; Oh, M.; Sung, Y.; (2010) Electrochemical detection of vascular endothelial growth factors (VEGFs) using VEGF antibody fragments modified Au NPs/ITO electrode. Biosensors and Bioelectronics, 25, 7, 1717-1722.

Kim, N.; Ji, G.E. (2006) Modulatory activity of Bifidobacterium sp. BGN4 cell fractions on immune cells, J. Microbiol. Biotechnol. 16, 584-589.

Kim, N.; Kim, D.K.; Cho, Y.J. (2009). Development of indirect-competitive quartz crystal microbalance immunosensor for C-reactive protein., Sensors and Actuators B: Chemical, 143, 1, 444-448.

Kim, N.; Kim, D.K.; Cho, Y.J. (2010) Gold nanoparticle-based signal augmentation of quartz crystal microbalance immunosensor measuring C-reactive protein., Current Applied Physics, 10, 4, 1227-1230.

Kim, N.; Park, I.S.; Kim, D.K. (2004). Characteristics of a label-free piezoelectric immunosensor detecting Pseudomonas aeruginosa, Sens. Actuators B: Chem. 100, 432-438.

Kim, N.; Park, I.S.; Kim, W.Y. (2007). Salmonella detection with a direct-binding optical grating coupler immunosensor, Sens. Actuators B: Chem. 121, 606-615.

Kim, P.Y.; Lee, B.Y.; Lee, J.; Hong, S.; Sim, S.J. (2009) Enhancement of sensitivity and specificity by surface modification of carbon nanotubes in diagnosis of prostate cancer based on carbon nanotube field effect transistors.,Biosensors and Bioelectronics, 24, 11, 3372-3378.

Kim, S.W.; Cheon, K.; Kim, C.H.; Yoon, J.H.; Hawke, D.H.; Kobayashi, R.; Prudkin, L.; Wistuba, I.I.; Lotan, R.; Hong, W.K.; Koo, J.S. (2007) Proteomics-based identification of proteins secreted in apical surface fluid of squamous metaplastic human tracheobronchial epithelial cells cultured by three-dimensional organotypic airliquid interface method. Cancer Res. 67, 14, 6565-6573.

Koo, J.S.; Yoon, J.H.; Gray, T.; Norford, D.; Jetten, A.M.; Nettesheim, P.; (1999). Restoration of the mucous phenotype by retinoic acid in retinoid-deficient human bronchial cell cultures: changes in mucin gene expression., Am. J. Respir. Cell Mol. Biol. 20, 1, 43-52.

Koskinen, J.O.; Vaarno, J.; Meltola, N.J.; Soini, J.T.; Hänninen, P.E.; Luotola, J.; Waris, M.E.; Soini, A.E. (2004) Fluorescent nanoparticles as labels for immunometric assay of Creactive protein using two-photon excitation assay technology, Anal. Biochem., $328,210-218$. 
Kovochich, M.; Xia, T.; Xu, J.; Yeh, J.I.; Nel, A.E.; (2007). In: M. Weisner, (Ed.), Toxicological Impact of Materials. Principles and Methods for the assessment of nanomaterial toxicity. Journal of the American Chemical Society 62, 1940, 2643-2657.

Kranz, A.; Mattfeldt, T. and Waltenberger, J. (1999). "Molecular mediators of tumor angiogenesis: enhanced expression and activation of vascular endothelial growth factor receptor KDR in primary breast cancer." Int J Cancer 84, 293-8.

Kumar, S.; Aaron, J.; Sokolov, K.; (2008). Directional conjugation of antibodies to nanoparticles for synthesis of multiplexed optical contrast agents with both delivery and targeting moieties. Nat. Protoc. 3, 2, 314-320.

Kurebayashi, J.; Tang, C. K.; Otsuki, T.; Kurosumi, M., Yamamoto, S.; Tanaka, K.; Mochizuki, M.; Nakamura, H. and Sonoo, H. (1999). Isolation and characterisation of a new human breast cancer cell line, KPL-4, expressing the Erb B family receptors and interleukin-6. Br. J. Cancer, 79, 707-717.

Kurosawa, S.; Nakamura, M.; Park, J.W.; Aizawa, H.; Yamada, K.; Hirata, M. (2004). Evaluation of a high-affinity QCM immunosensor using antibody fragmentation and 2-methacryloyloxyethyl phosphorylcholine (MPC) polymer, Biosens. Bioelectron. 20, 1134-1139.

Kwon, S.J.; Yang, H.; Jo, K.; Kwak, J. (2008). An electrochemical immunosensor using paminophenol redox cycling by $\mathrm{NADH}$ on a self-assembled monolayer and ferrocene-modified Au electrodes, Analyst 133, 1599-1604.

Lackie, P.M. (1996) Immunogold silver staining for light microscopy. Histochem Cell Biol 106:9-17

Ladd, J.; Boozer, C.; Yu, Q.M.; Chen, S.F.; Homola, J.; Jiang, S. (2004) DNA-directed protein immobilization on mixed self-assembledmonolayers via a streptavidin bridge, Langmuir, 20, 8090-8095.

Ladd, J.; Lu, H.; Taylor, A.D.; Goodell, V.; Disis, M.L.; Jiang, S. (2009) Direct detection of carcinoembryonic antigen autoantibodies in clinical human serum samples using a surface plasmon resonance sensor., Colloids and Surfaces B: Biointerfaces, 70, 1, 16.

Landis, S.H.; Murray, T.; Bolden, S.; Wingo, P.A. (1999) Cancer statistics., CA Cancer J Clin. $49,1,8-31,1$.

Lee, K.N.; Jung, S.W.; Shin, K.S., Kim, W.H.; Lee, M.H.; Seong, W.K. (2007) Fabrication of suspended silicon nanowire arrays. 4, 642-8.

Lee, M.H.; Lee, D.H.; Jung, S.W.; Lee, K.N.; Park, Y.S.; Seong, W.K. (2010) Measurements of serum C-reactive protein levels in patients with gastric cancer and quantification using silicon nanowire arrays., Nanomedicine: Nanotechnology, Biology and Medicine, 6, 1, 78-83.

Lee, Y.; Garcia, M.A.; Huls, N.A.F.; S, Sun. (2010). "Synthetic Tuning of Catalytic Properties of $\mathrm{Au}-\mathrm{Fe}_{3} \mathrm{O}_{4}$ Nanoparticles". Angew. Chem. Int. Ed. 49, 1271.

Li, H.; Wei, Q.; Wang, G.; Yang, M.; Qu, F.; Qian, Z. (2011). Sensitive electrochemical immunosensor for cancer biomarker with signal enhancement based on nitrodopamine-functionalized iron oxide nanoparticles., Biosensors and Bioelectronics, 26, 6, 3044-3049. 
Li, X.; Yuan, R.; Chai, Y.; Zhang, L.; Zhuo, Y.; Zhang, Y. (2006). Amperometric immunosensor based on toluidine blue/nano-Au through electrostatic interaction for determination of carcinoembryonic antigen. Journal of Biotechnology, 123, 3, 356-366.

Liang, R.Q.; Tan, C.Y.; Ruan, K.C. (2004). Colorimetric detection of protein microarrays based on nanogold probe coupled with silver enhancement., Journal of Immunological Methods, 285, 2, 157-163.

Liao, Y.; et al. (2010). Immunosensor based on Nf-Cys composite membrane Anal. Biochem. 402, 47-53.

Lilja, H.; Cronin, A.M.; Scardino, P.T.; Dahlin, A.; Bjartell, A.; Berglund, G.; Ulmert, D.; Vickers. A.J. (2008) A Single PSA Predicts Prostate Cancer Up To 30 Years Subsequently, Even In Men Below Age 40., The Journal of Urology, 179, 4, 206-207.

Lim, C.T.; Zhang, Y. (2007) Bead-based microfluidic immunoassays: The next generation.,Biosensors and Bioelectronics, 22, 7, pp. 1197-1204.

Lim, T.K .; Matsunaga T. (2001). Construction of electrochemical flow immunoassay system using capillary columns and ferrocene conjugated immunoglobulin $\mathrm{G}$ for detection of human chorionic gonadotrophin. Biosensors and Bioelectronics, 16, 9-12, 10631069.

Limoges, B.; Marchal, D.; Mavré, F.; Savéant, J.M. (2006). High amplification rates from the association of two enzymes confined within a nanometric layer immobilized on an electrode: modeling and illustrating example, J. Am. Chem. Soc. 128 pp.6014-6015.

Limoges, B.; Marchal, D.; Mavré, F.; Savéant, J.M. (2008). Theory and practice of enzyme bioaffinity electrodes. chemical, enzymatic, and electrochemical amplification of in situ product detection, J. Am. Chem. Soc. 130 pp.7276-7285.

Lin, W.J.; Liao, C.S.; Zhang,J.H.; Tsai, Y.C. (2009). Graphene modified basal and edge plane pyrolytic graphite electrodes for electrocatalytic oxidation of hydrogen peroxide and nicotinamide adenine dinucleotide. Electrochem. Commun. 11, 2153-2156.

Lin, Y.Y.; Wang, J.; Liu, G.; Wu, H.; Wai, C.M.; Lin, Y. (2008). A nanoparticle label/immunochromatographic electrochemical biosensor for rapid and sensitive detection of prostate-specific antigen. Biosensors and Bioelectronics, 23, 11, 16591665.

Lippman, M.E.; Harrison's Principles of Internal Medicine, 2008.

Liu, C.; Alwarappan, S. ; Chen, Z.F.; Kong, X.X.; Li, C.Z. (2010) Membraneless enzymatic biofuel cells based on graphene nanosheets, Biosens. Bioelectron., 25, 1829-1833.

Liu, G.; Gooding, J.J. (2009) Towards the fabrication of label-free amperometric immunosensors using SWNTs., Electrochemistry Communications, 11, 10, 19821985.

Liu, G.; Lin, Y. (2007). Nanomaterial labels in electrochemical immunosensors and immunoassays., Talanta, 74, 3, 308-317.

Liu, G.; Lin, Y.Y.; Wang, J.; Wu, H.; Wai, C.M. and Lin Y. (2007). "Disposable Electrochemical Immunosensor Diagnosis Device Based on Nanoparticle Probe and Immunochromatographic Strip." Analytical Chemistry 79, 20, 7644-7653. 
Liu, J.; Cheng, L.; Liu, B.; Dong, S.J.; (2000). Covalent modification of a glassy carbon surface by 4 -aminobenzoic acid and its application in fabrication of a polyoxometalatesconsisting monolayer and multilayer films. Langmuir 16, 7471-7476.

Liu, K.G.; Yuan, R.; Chai, Y.Q.; Tang, D.P.; An, H.Z. Chiral resolution of phenylalanine by dPhe imprinted membrane considering rejection property Bioprocess and Biosystems Engineering, 33, (1), 79-86.

Liu, K.P.; Zhang, J.J.; Yang, G.H.; Wang, C.M.; Zhu, J.J. (2010). Direct electrochemistry and electrocatalysis of hemoglobin based on poly(diallyldimethylammonium chloride) functionalized graphene sheets/room temperature ionic liquid composite film, Electrochem. Commun. 12, 402-405.

Liu, M.; Jia, C.; Jin, Q.; Lou, X.; Yao, S.; Xiang, J.; Zhao, J. (2010) Novel colorimetric enzyme immunoassay for the detection of carcinoembryonic antigen., Talanta, 81 , 4-5, 1625-1629.

Liu, S.; Zhang, X.; Wu, Y.; Tu, Y.; He, L. (2008). Prostate-specific antigen detection by using a reusable amperometric immunosensor based on reversible binding and leasing of HRP-anti-PSA from phenylboronic acid modified electrode., Clinica Chimica Acta, 395, 1-2, 51-56.

Liu, S.Q.; Xu, J.J.; Chen, H.Y. (2002). Electrochemical behavior of nanosized Prussian blue self-assembled on Au electrode surface Electrochemistry Communications, 4, 5, 421-425.

Liu, Y.; Lei, J.; Ju, H. (2008). Amperometric sensor for hydrogen peroxide based on electric wire composed of horseradish peroxidase and toluidine blue-multiwalled carbon nanotubes nanocomposite. Talanta, 74, 4, 965-970.

Liu, Y.; Wang, M.; Zhao, F.; Xu, Z.; Dong, S. (2005). The direct electron transfer of glucose oxidase and glucose biosensor based on carbon nanotubes/chitosan matrix. Biosensors and Bioelectronics, 21, 6, 984-988.

Liu, Z.; Robinson, J.T.; Sun, X.; and Dai, H. (2008). PEGylated Nanographene Oxide for Delivery of Water-Insoluble Cancer Drugs. J. Am. Chem. Soc. 130, 10876-10877.

Liu, Z.; Yuan, R.; Chai, Y.; Zhuo, Y.; Hong, C.; Yang, X. (2008). Highly sensitive, reagentless amperometric immunosensor based on a novel redox-active organic-inorganic composite film. Sensors and Actuators B: Chemical, 134, 2, 625-631.

Lu, G.; Jiang, L.; Song, F.; Liu C. and Jiang, L. (2005) Determination of uric acid and norepinephrine by chitosan-multiwall carbon nanotube modified electrode, Electroanalysis 17, 901-905.

Lupu, S.; Mihailciuc, C.; Pigani, L.; Seeber, R.L.; Totir, N.; Zanardi, C. (2002). Electrochemical preparation and characterisation of bilayer films composed by Prussian Blue and conducting polymer, Electrochem. Commun. 4, 753-758.

Lvov, Y. (2001). Thin-film nanofabrication by alternate adsorption of polyions, nanoparticles, and proteins, in: R.W. Nalwa (Ed.), Handbook of Surfaces and Interfaces of Materials, 3, Academic Press, San Diego, 170-189.

Maeng, J.H.; Lee, B.C.; Ko, Y.J.; Cho, W.; Ahn, Y.; Cho, N.G.; Lee, S.H.; Hwang, S.Y. (2008). A novel microfluidic biosensor based on an electrical detection system for alphafetoprotein. 1319-1325. 
Mak, K.W.; Wollenberger, U.; Scheller, F.W.; Scheller; Renneberg; (2003). An amperometric bi-enzyme sensor for determination of formate using cofactor regeneration, Biosens. Bioelectron. 18, 1095-1100.

Mario, P.; Ali, T.; Wanqin, J.; Judit, S.; Bernd, T. (2003) Self-assembled films of prussian blue and analogues: optical and electrochemical properties and application as ionsieving membranes, Chem. Mater. 15, 245-254.

Mauritz, K. A.; Moore, R. B. (2004) "State of understanding of Nafion." Chem. Rev., 104, 4535 4585.

McAllister, M. J.; Li, J. L.; Adamson, D. H.; Schniepp, H. C.; Abdala, A. A.; Liu, J.; HerreraAlonso, M.; Milius, D. L.; CarO,R.; Prud'homme, R. K. (2007). Single Sheet Functionalized Graphene by Oxidation and Thermal Expansion of Graphite. Chem. Mater., 19, 4396-4404.

McBride, J.D.; Cooper, M.A. (2008). A high sensitivity assay for the inflammatory marker Creactive protein employing acoustic biosensing, J. Nanobiotechnol., 6, 5.

Meyer, M.H.F.; Hartmann, M.; Krause, H.J.; Blankenstein, G.; Mueller-Chorus, B.; Oster, J.; Miethe, P.; Keusgen, M. (2007). CRP determination based on a novel magnetic biosensor, Biosens. Bioelectron. 22, 973-979.

Meyer, M.H.F.; Hartmann, M.; Keusgen, H.J. (2006)SPR-based immunosensor for the CRP detection-A new method to detect a well known protein., Biosensors and Bioelectronics, 21, 10, 1987-1990.

Meyer, M.H.F.; Hartmann, M.; Keusgen, M. (2006). SPR-based immunosensor for the CRP detection - A new method to detect a well known protein, Biosens. Bioelectron. 21, 1987-1990.

Milka, P.; Krest, I.; Keusgen, M.; (2000). Immobilization of alliinase on porous aluminium oxide. Biotechnol. Bioeng. 3, 344-348.

Mosbach,K. (1994). Molecular imprinting. Trends in Biochemical Sciences 19, 9-14.

Mukundan, H.; Kubicek, J.Z.; Holt, A.; Shively, J.E.; Martinez, J.S.; Grace, K.; Grace, W.K.; Swanson, B.I. (2009) Planar optical waveguide-based biosensor for the quantitative detection of tumor markers., Sensors and Actuators B: Chemical, 138, 2, 453-460

Munge, B.; Liu, G.; Collins, G.; Wang, J. (2005) Multiple enzyme layers on carbon nanotubes for electrochemical detection down to 80DNAcopies, Anal. Chem. 77 pp. 4662 4666.

Munge, B.; Liu, G.; Collins, G.; Wang, J. (2005). Multiple enzyme layers on carbon nanotubes for ultrasensitive electrochemical detection down to 80 DNA copies, Anal. Chem. 77 pp.4662-4666.

Nagatani, N.; Tanaka, R.; Yuhi, T.; Endo, T.; Kerman, K.; Takamura, Y.; Tamiya, E. (2006). Gold nanoparticle-based novel enhancement method for the development of highly sensitive immunochromatographic test strips., Science and Technology of Advanced Materials, 7, 3, 270-275.

Nam, J.M.; Thaxton, C.S.; Mirkin, C.A.; (2003) Nanoparticle-Based Bio-Bar Codes for the Ultrasensitive Detection of Proteins., Science 301, 1884.

Norton, J.D.; White, H.S.; Feldberg, S.W. (1990) Effect of the electrical double layer on voltammetry at microelectrodes., J. Phys. Chem., 94 (17), 6772-6780. 
O'Sullivan, C.K.; Guilbault, G.G. (1999) Commercial quartz crystalmicrobalances - theory and applications. Biosens Bioelectron. 14,663-70.

Ohta, T.; Bostwick, A.; Seyller, T.; Horn, K.; Rotenberg, E. (2006) Controlling the Electronic Structure of Bilayer Graphene. Science 313, 951-954.

Oikawa, S.; Inuzuka, C.; Kuroki, M.; Matsuoka, Y.; Kosaki, G.; Nakazato, H. (1989) Cell adhesion activity of non-specific cross-reacting antigen (NCA) and carcinoembryonic antigen (CEA) expressed on CHO cell surface: Homophilic and heterophilic adhesion., Biochemical and Biophysical Research Communications, 164, 1, 39-45.

Ostuni, E.; Chapman, R.G.; Holmlin, R.E.; Takayama, S.; Whitesides, G.M. (2001). A survey of structure-property relationships of surfaces that resist the adsorption of protein, Langmuir, 17, 5605-5620.

Panini, N.V.; Messina, G.A.; Salinas, E.; Fernández, H.; Raba, J. (2008). Integrated microfluidic systems with an immunosensor modified with carbon nanotubes for detection of prostate specific antigen (PSA) in human serum samples., Biosensors and Bioelectronics, 23, 7, 1145-1151.

Panteghini, M.; (2000). Present issues in the determination of troponins and other markers of cardiac damage. Clin. Biochem. 33, 161.

Park, I.-S.; Kim, N. (1998). Thiolated Salmonella antibody immobilization onto the gold surface of piezoelectric quartz crystal, Biosens. Bioelectron. 13, 1091-1097.

Park, I.-S.; Kim, N.; (2006) Development of a chemiluminescent immunosensor for chloramphenicol, Anal. Chim. Acta, 578, 19-24.

Pathak, S.; Choi, S.K.; Arnheim, N; Thompson, M.E. (2001) Hydroxylated quantum dots as luminescent probes for in situ hybridization. J. Am. Chem. Soc.123, 4103-4104.

Patolsky, F.; Zheng, G.; Hayden, O.; Lakadamyali, M.; Zhuang, X.; Lieber, C.M. (2004) Electrical detection of single viruses. Proc Natl Acad Sci U S A, 101, 14017-22.

Patolsky, F.; Zheng, G.; Lieber, C.M. (2006). Fabrication of silicon nanowire devices for ultrasensitive, label-free, real-time detection of biological and chemical species. Nat Protocol.,1, 1711-24.

Pauling, L. (2009). A theory of the structure and process of formation of antibodies, redox multi-wall carbon nanotube composite, Electrochim. Acta 54, 4149-4154.

Phadtare, S.; Vinod, V.P.; Mukhopadhyay, K.; Kumar, A.; Rao, M.; Chaudhari, R.V.; Sastry, M.; (2004). Immobilization and biocatalytic activity of fungal protease on gold nanoparticle-lodaed zeolite microspheres. Biotechnol. Bioeng. 6, 629-637.

Piletsky, S.A.; Alcock, S. Turner, A.P.F. (2001) Molecular imprinting: at the edge of the third millennium, Trends in Biotechnology 19, 9-12.

Porter, M.D.; Bright, T.B.; Allara, D.L.; Chidsey, C.E.D. (1987). Spontaneously organized molecular assemblies. 4. Structural characterization of normal-alkyl thiol monolayers on gold by optical ellipsometry, infrared-spectroscopy, and electrochemistry, Journal of the American Chemical Society 109, 3559-3568.

Prabhulkar, S.; Alwarappan, S.; Liu, G.; Li, C.Z. (2009). Amperometric micro-immunosensor for the detection of tumor biomarker., Biosensors and Bioelectronics, 24, 12, 35243530 . 
Preechaworapuna, Z.; Dai, Y.; Xiang, O.; Chailapakulb, J.; Wang, (2008). Investigation of the enzyme hydrolysis products of the substrates of alkaline phosphatase in electrochemical immunosensing, Talanta 76, 424-431.

Qian, J.; Zhou, Z.; Cao, X.; Liu. S. (2010) Electrochemiluminescence immunosensor for ultrasensitive detection of biomarker using $\mathrm{Ru}(\mathrm{bpy}) 3^{2+}$-encapsulated silica nanosphere labels., Analytica Chimica Acta, 665, 1, 32-38.

Qiao, Y.L.; Tockman, M.S.; Li, L.; Erozan, Y.S., Yao, S.X.; Barrett, M.J.; Zhou, W.H.; Giffen, C.A.; Luo, X.C.; Taylor, P.R. (1997). Risk factors and early detection of lung cancer in a cohort of Chinese tin miners. Cancer Epidemiol. Biomarkers Prev. 6, 893-900.

Qu, B.; Chu, X.; Shen, G.; Yu, R.; (2008). A novel electrochemical immunosensor based on colabeled silica nanoparticles for determination of total prostate specific antigen in human serum.,Talanta, 76, 4, pp. 785-790.

Qu, B.; Chu, X.; Shen, G.; Yu, R.; (2008). A novel electrochemical immunosensor based on colabeled silica nanoparticles for determination of total prostate specific antigen in human serum., Talanta, 76, 4, pp.785-790.

Quershi, A.; Gurbuz, Y., Kang, W.; Davidson J.L.; (2009) A novel interdigitated capacitor based biosensor for detection of cardiovascular risk marker., Biosensors and Bioelectronics, 25, 4, pp. 877-882.

Qureshi, A.; Niazi, J.; Kallempudi, S.; Gurbuz, Y.(2009). Label-free capacitive biosensor for sensitive detection of multiple biomarkers using gold interdigitated capacitor arrays. Biosensors and Bioelectronics, 25, 10, pp. 2318-2323.

Rahman, A.; Won, M.S.; Shim, Y.B. (2005). The potential use of hydrazine as an alternative to peroxidase in a biosensor: comparison between hydrazine and HRP-based glucose sensors., Biosensors and Bioelectronics, 21, 2, 257-265.

Rossier, J.; Reymond, F.; Michel, P.E.; (2002). Polymer microfluidic chips for electrochemical and biochemical analyses. Electrophoresis 23, 858.

Ruohola, J.K.; Valve, E.M.; Karkkainen, M.J.; Joukov, V.; Alitalo, K.; Härkönen, P.L. (1999). Vascular endothelial growth factors are differentially regulated by steroid hormones and antiestrogens in breast cancer cells., Molecular and Cellular Endocrinology, 149, 1-2, 29-40.

Rusling, J.F.; Sotzing, G.; Papadimitrakopoulosa, F. (2009). Designing nanomaterialenhanced electrochemical immunosensors for cancer biomarker proteins., Bioelectrochemistry, 76, 1-2, 189-194

Sánchez, C.F.; Gallardo-Soto, A.M.; Rawson, K.; Nilsson, O.; McNeil, C.J. (2004). Quantitative impedimetric immunosensor for free and total prostate specific antigen based on a lateral flow assay format ., Electrochemistry Communications, 6, 2, 138-143

Sánchez, C.F.; Gallardo-Soto, A.M.; Rawson, K.; Nilsson, O.; McNeil, C.J.; Leung, H.Y.; Gnanapragasam, V. (2005) One-step immunostrip test for the simultaneous detection of free and total prostate specific antigen in serum., Journal of Immunological Methods, 307, 1-2, 1-12

Saravan, K.S.; Gul, O.; Basaga, H.; Sezerman, U.; Gurbuz, Y. (2008). C-reactive protein as a risk factor versus risk marker.,Sens. Lett. 6 (6), 873-877. 
Sato, K.; Yamanaka, M.; Takahashi, H.; Tokeshi, M.; Kimura, H.; Kitamori, T.; (2002). Microchip-based immunoassay system with branching multichannels for simultaneous determination of interferon-ү. Electrophoresis 23, 734-739.

Scheller, F.W.; Bauer, C.G.; Makower, A.; Wollenberger, U.; Warsinke, A.; Bier, F.F. (2001) Coupling of immunoassays with enzymatic recycling electrodes, Anal. Lett., 34, 1233-1245.

Scripps Laboratories, http://www.scrippslabs.com/datatables/proteinabsorbance.html, 2007.

Seiwert, B.; Karst, U. (2008). Ferrocene-based derivatization in analytical chemistry. Anal. Bioanal. Chem. 390 (1), 181-200.

Sellergren, B. (2001) Molecularly Imprinted Polymers, Man-made Mimics of Antibodies and Their Application in Analytical Chemistry, Elsevier, New York,.

Sellergren, B.; Shea, K.J. (1994). Enantioselective ester hydrolysis catalyzed by imprinted polymers, Tetrahedron-Asymmetry 5 pp.1403-1406.

Shan, C.S.; Yang, H.F.; Song, J.F.; Han, D.X.; Ivaska, A.; Niu, L. (2009). Direct electrochemistry of glucose oxidase and biosensing for glucose based on grapheme, Anal. Chem., 81, 2378-2382.

Shankaran, D.R.; Shim, Y.-B. (2002). An amperometric sensor for hydrogen peroxide based on a (3-mercaptopropyl)trimethoxysilane self-assembled layer containing hydrazine. Electroanalysis 14, 704-707.

Shi, H.; Xia, T.; Nel, A.E.; Yeh, J.I.; (2007). Part II: coordinated biosensors--development of enhanced nanobiosensors for biological and medical applications. Nanomedicine 2 (5), 599-614.

Shi, W.; Ma, Z. (2011). A novel label-free amperometric immunosensor for carcinoembryonic antigen based on redox membrane. Biosensors and Bioelectronics, 26, 6 , 3068-3071.

Shiddiky, M.J.A.; Rahman, M.A.; Shim, Y.-B. (2007a). Trace Analysis of DNA: Preconcentration, Separation, and Electrochemical Detection in Microchip Electrophoresis Using Au Nanoparticles. Anal. Chem. 79, 3724-3733.

Shiddiky, M.J.A.; Rahman, M.A.; Shim, Y.B. (2007b) Hydrazine-Catalyzed Ultrasensitive Detection of DNA and Proteins. Anal. Chem. 79, 6886-6890.

Singh, A.K.; Kilpatrick, P.K.; Carbonell, R.G. (1996). Application of Antibody and Fluorophore-Derivatized Liposomes to Heterogeneous Immunoassays for D-dimer. Biotechnol. Prog. 12, 272-280.

Song, Z.; Yuan, R.; Chai, Y.; Yin, B.; Fu, P.; Wang, J. (2010). Multilayer structured amperometric immunosensor based on gold nanoparticles and Prussian blue nanoparticles/nanocomposite functionalized interface., Electrochimica Acta, 55, 5, 1778-1784.

Spinks, G.M.; Shin, S.R.; Wallace, G.G.; Whitten, P.G.; Kim, S.I.; Kim, S.J. (2006) Mechanical properties of chitosan/CNT microfibers obtained with improved dispersion., Sensors and Actuators B: Chemical, 115, 2, 678-684.

Stephan, C.; Klaas, M.; Muller, C.; Schnorr, D.; Loening, S.A.; Jung, K. (2006) Interchangeability of measurements of total and free prostate-specific antigen in serum with 5 frequently used assay combinations: an update. Clin. Chem., 52, 59 64 
Strein, T.G.; and Ewing, A.G. (1992). "Characterization of submicron-sized carbon electrodes insulated with a phenol-allylphenol copolymer." Analytical Chemistry, 64, 13681373.

Su, H.L.; Yuan, R.; Chai, Y.Q.; Zhuo, Y.; Hong, C.L.; Liu, Z.Y.; Yang, X. (1995) Multilayer structured amperometric immunosensor built by self-assembly of a graphite electrodes with mechanically immobilized Prussian Blue, J. Electroanal. Chem., 398, 23-35

$\mathrm{Su}$, X.D.; Li, S.F.Y.; and O'Shea, S.J. (2001). Gold nanoparticle and silver enhancement reaction amplified microgravimetric biosensor., Chemical Communications , 8, 755756.

Sun, S.J.; Yao, Y.Z.; Wang, T.; Li, Y.C.; Ma, X.L.; Zhang, L.Y. (2009). Nanosilver, DNAfunctionalized immunosensing probes for electrochemical immunoassay of alpha-fetoprotein, Microchim. Acta 166, 83-88.

Takahashi, S.; Reddy, S.V.; Chirgwin, J.M.; Devlin, R.; Haipek,C.; Anderson, J.; Roodman, G.D. (1994). "Cloning and identification of annexin II as an autocrine/paracrine factor that increases osteoclast formation and bone resorption". J. Biol. Chem. 269 (46): 28696-701. PMID 7961821

Tan, F.; Yan, F.; Ju, H.X. (2006). A designer ormosil gel for preparation of sensitive immunosensor for carcinoembryonic antigen based on simple direct electron transfer. Electrochem Commun, 8:1835-9.

Tang, D.; Ren, J. (2008). In Situ Amplified Electrochemical Immunoassay for Carcinoembryonic Antigen Using Horseradish Peroxidase-Encapsulated Nanogold Hollow Microspheres as Labels. Anal. Chem. 80, 8064-8070.

Tang, D.;Yuan, R.; Chai, Y. (2008). Ultrasensitive Electrochemical Immunosensor for Clinical Immunoassay Using Thionine-Doped Magnetic Gold Nanospheres as Labels and Horseradish Peroxidase as Enhancer. Anal. Chem. 80, 1582-1588.

Tang, H.; Chen, J.; Nie, L.; Kuang, Y.; Yao, S. 2007) A label-free electrochemical immunoassay for carcinoembryonic antigen (CEA) based on gold nanoparticles (AuNPs) and nonconductive polymer film., Biosensors and Bioelectronics, 22, 6, 1061-1067.

Tang, J.; Huang, J.; Su, B.; Chen, H.; Tang, D.; (2011). Sandwich-type conductometric immunoassay of alpha-fetoprotein in human serum using carbon nanoparticles as labels., Biochemical Engineering Journal, 53, 2, 223-228.

Tang, Q.; Xu, C.H.; Shi, S.Q.; Zhou, L.M. (2004). Formation and characterization of proteinpatterns on the surfaces with different properties, Synthetic Metals 147, 247252.

Thomson, D.M.P.; Krupey, J.; Freedman, S.O.; Gold, P. (1969). The carcinoembryonic antigen (CEA) radioimmunoassay. Proc. Natl. Acad. Sci. 64, 161-167.

Tiefenauer, L.X.; Kossek, S.; Padeste, C.; Thiébaud, P. (1997) Towards amperometric immunosensor devices., Biosensors and Bioelectronics, 12, 3, 213-223.

Tothill, I.E.; Turner, A.P.F. (2003). Biosensors. In: B Caballero, L Trugo , P Finglas, (Eds) Encyclopaedia of food sciences and nutrition. 2nd ed. Academic Press; ISBN: 0-12227055-X. 
Triroj, N.; Jaroenapibal, P.; Shi, H.; Yeh, J.I.; Beresford, R. (2011) Microfluidic chip-based nanoelectrode array as miniaturized biochemical sensing platform for prostatespecific antigen detection., Biosensors and Bioelectronics, 26, 6, 2927-2933.

Tseng, C.-H.; Wang, C.C.; Chen, C.-Y. (2007). Functionalizing Carbon Nanotubes by Plasma Modification for thenPreparation of Covalent-Integrated Epoxy Composites. Chem. Mater. 19, 308-315.

Uludağ, Y.; Tothill, I.E. (2010). Development of a sensitive detection method of cancer biomarkers in human serum (75\%) using a quartz crystal microbalance sensor and nanoparticles amplification system. Talanta, 82, 1, 277-282.

Valat, C.; Limoges, B.; Huet, D.; Romette, J.L. (2000). Functionalizing Carbon Nanotubes by Plasma Modification for the Preparation of Covalent-Integrated Epoxy Composites. Anal. Chim. Acta 404, 187-194.

Valden, M.; Lai, X.; Goodman, D.W. (1998). Onset of Catalytic Activity of Gold Clusters on Titania with the Appearance of Nonmetallic Properties. Science 281, 1647-1649.

Verma, S.; Yeh, E.T. (2003). C-reactive protein and atherothrombosis-beyond a biomarker: an actual partaker of lesion formation, Am. J. Physiol. 285, R1253-R1256.

Vikholm-Lundin, I.; Albers, W.M. (2006) Site-directed immobilization of antibody fragments for detection of C-reactive protein, Biosens. Bioelectron. 21, 1141-1148.

Viswanathan, S.; Rani, C.; Anand, A.V.; Ho, J.A. (2009). Disposable electrochemical immunosensor for carcinoembryonic antigen using ferrocene liposomes and MWCNT screen-printed electrode., Biosensors and Bioelectronics, 24, 7, 1984-1989.

Vlatakis, G.; Andersson, L.I.; Muller, R.; Mosbach, K. (1993) Drug assay using antibody mimics made by molecular imprinting, Nature, 361, 645-647.

Wang, A.; Liang, X.; McAllister, J.P.2nd.; Li, J.; Brabant, K.; Black, C.; Finlayson, P.; Cao, T.; Tang, H.; Salley, S.O.; Auner, G.W.; Simon, Ng.K. (2007). Stability of and inflammatory response to silicon coated with a fluoroalkyl self-assembled monolayer in the central nervous system. J Biomed Mater Res A ,81(2):363-72.

Wang, C.; Daimon, H.; Sun, S.H. (2009). Dumbbell-like $\mathrm{Pt}-\mathrm{Fe}_{3} \mathrm{O}_{4}$ Nanoparticles and Their Enhanced Catalysis for Oxygen Reduction Reaction. Nano Lett. 9, 1493-1496.

Wang, C.; Xu, C.J.; Zeng, H.; Sun, S.H. (2009). A General Approach to Noble Metal-Metal Oxide Dumbbell Nanoparticles and Their Catalytic Application for CO Oxidation. Adv. Mater. 21, 3045-3052.

Wang, H.L.; Li, W.; Jia, Q.X.; Akhadov, E. (2007). Tailoring Conducting Polymer Chemistry for the Chemical Deposition of Metal Particles and Clusters. Chem. Mater. 19, 520525.

Wang, J.; Liu, G.; Jan, M.; (2004) Ultrasensitive electrical biosensing of proteins and DNA: carbon-nanotube derived amplification of the recognition and transduction events, J. Am. Chem. Soc.,126, 3010-3011.

Wang, J.; Pamidi, P.V.A.; Rogers, K.R. (1998). Sol-gel-derived thick-film amperomertic immunosensors. Anal. Chem. 70, 1171-1175.

Wang, J; Krause, R.; Block, K.; Musameh, M.; Mulchandani, A.; Schöning, M.J. (2003). Flow injection amperometric detection of OP nerve agents based on an organophosphorus-hydrolase biosensor detector Original Research Article Biosensors and Bioelectronics, 18, 2-3, 255-260 
Wang, L.; Gan, X.X. (2009). Antibody-functionalized magnetic nanoparticles for electrochemical immunoassay of _-1-fetoprotein in human serum, Microchim. Acta 164, 231-237.

Wang, Y.; Lu, J.; Tang, L.H.; Chang, H.X.; Li, J.H. (2009). Graphene oxide amplified electrogenerated chemiluminescence of quantum dots and its selective sensing for glutathione from thiol-containing compounds. Anal. Chem. 81, 9710-9715.

Wang, Y.; Zhang, Z.; Jain, V.; Yi, J.; Mueller, S.; Sokolov, J.; Liu, Z.; Levon, K.; Rigas, B.; Rafailovich, M.H. (2010) Potentiometric sensors based on surface molecular imprinting: Detection of cancer biomarkers and viruses. Sensors and Actuators B: Chemical, 146, 1, 381-387.

Wang, Y.D.; Joshi, P.P.; Hobbs, K.L.; Johnson, M.B.; Schmidtke, D.W. (2006). Nanostructured biosensors built by layer-by-layer electrostatic assembly of enzyme-coated singlewalled carbon nanotubes and redox polymers. Langmuir 22, 9776-9783.

Wang,J.; Liu, G.; Engelhard, M.H.; and Lin, Y. (2006). "Sensitive Immunoassay of a Biomarker Tumor Necrosis Factor-[alpha] Based on Poly(guanine)-Functionalized Silica Nanoparticle Label." Analytical Chemistry 78(19):6974-6979.

Watson, L.; Maynard, P.; Cullen, D.; Sethi, R.; Brettle, J.; Lowe, C. (1987). Microelectronic conductimetric biosensor, Biosensors. 3, 101-115.

Wei, Q.; Mao, K.; Wu, D.; Dai, Y.; Yang, J.;Du, B.; Yang, M.; Li, H. (2010) A novel label-free electrochemical immunosensor based on graphene and thionine nanocomposite., Sensors and Actuators B: Chemical, 149, 1, 314-318.

Wei, Q.; Xiang, Z.; He, J.; Wang, G.; Li, H.; Qian, Z.; Yang, M.; (2010). Dumbbell-like Au$\mathrm{Fe}_{3} \mathrm{O}_{4}$ nanoparticles as label for the preparation of electrochemical immunosensors., Biosensors and Bioelectronics, 26, 2, 627-631.

Weinhold, U.R. (1997). Interleukin-6-dependent and -independent regulation of the human C-reactive protein gene. Biochem. J. 327, 425-429.

Weipoltshammer, K.; Schöfer,C.; Almeder,M.; and Wachtler,F. (2000). Signal enhancement at the electron microscopic level using Nanogold and gold-based autometallography. Histochem Cell Biol 114, 489-495.

White, I.M.; Gohring, J.; Fan, X. (2007). SERS-based detection in an optofluidic ring resonator platform, Opt. Express. 15, 17433-17442.

White, I.M.; Oveys, H.; Fan, X. (2006) Liquid-core optical ring-resonator sensors, Opt. Lett. 31, 1319-1321.

Wu, H.;Liu, G.;Wang, J.; Lin, Y. (2007). Quantum-dots based electrochemical immunoassay of interleukin-1a ., Electrochemistry Communications, 9,7, 1573-1577.

Wu, J.; Tang, J.; Dai, Z.;Yan, F.jJu, H.; Murr, N.E. (200\& A disposable electrochemical immunosensor for flow injection immunoassay of carcinoembryonic antigen., Biosensors and Bioelectronics, 22, 1, 102-108.

Wu, J.F.; Xu, M.Q.; Zhao, G.C. (2010) Graphene-based modified electrode for the direct electron transfer of cytochrome c and biosensing, Electrochem. Commun. 12 (2010) 175-177.

Wu, J.F.; Xu, M.Q.; Zhao, G.C. (2010) Graphene-based modified electrode for the direct electron transfer of cytochrome c and biosensing, Electrochem. Commun., 12, 175177. 
Wu, Y.; Liu, S.; He, L. (2010). Activators generated electron transfer for atom transfer radical polymerization for immunosensing. Biosensors and Bioelectronics, 26, 3, 970-975.

Wulff, G. (1995). Molecular imprinting in cross-linked materials with the aid of molecular templates - a way towards artificial antibodies, Angewandte Chemie-International Edition in English, 34,1812-1832.

Xian, Y.Z.; Hua, Y.; Liu, F.; Xian, Y.; Feng, L.J.; Jin, L.T. (2007). Template synthesis of highly ordered Prussian blue array and its application to the glucose biosensing. Biosens. Bioelectron. 22, 2827-2833.

Xu, Z.C.; Shen, C.M.; Hou, Y.L.; Gao, H.J.; Sun, S.H. (2009). Oleylamine as Both Reducing Agent and Stabilizer in a Facile Synthesis of Magnetite Nanoparticles. Chem. Mater. 21, 1778.

Xue, M. ; Li, J.; Lu, Z.; Ko, P. K. and Chan M. (2002) "Array-Based Electrical Detector of Integrated DNA Identification System for Genetic Chip Applications", Proceedings of the 32nd European Solid-State Device Research Conference (ESSDERC 2002), 483-486, Firenze, Italy

Yakovleva, J.; Davidsson, R.; Bengtsson, M.; Laurell, T.; Emneus, J. (2003). Microfluidic enzyme immunosensors with immobilised protein $A$ and $G$ using chemiluminescence detection. Biosens. Bioelectron. 19, 21-34.

Yang, F.; Ruan, C.M.; Xu, J.S.; Lei, C.H.; Deng, J.Q. (1998). Anamperometric biosensor using toluidine blue as an electron transfermediator intercalated in a-zirconium phosphate-modifiedhorseradish peroxidase immobilization matrix. Fresenius J. Anal.Chem. 361, 115-118.

Yang, L.; Ren, X.; Tang, F.; Zhang, L. (2009). A practical glucose biosensor based on $\mathrm{Fe}_{3} \mathrm{O}_{4}$ nanoparticles and chitosan/nafion composite film., Biosensors and Bioelectronics, $25,4,889-895$.

Yang, M.; Javadi, A.; Li, H.; Gong, S. (2010). Sensitive electrochemical immunosensor for the detection of cancer biomarker using quantum dot functionalized graphene sheets as labels

Sensors and Actuators B: Chemical,In Press, Corrected Proof, Available online 2 December 2010.

Yang, M.; Javadi, A.; Li, H.; Gong, S. (2010). Ultrasensitive immunosensor for the detection of cancer biomarker based on graphene sheet.,Biosensors and Bioelectronics, 26, 2, 560-565.

Yang, X.; Guo, Y.; Wang, A. (2010). Luminol/antibody labeled gold nanoparticles for chemiluminescence immunoassay of carcinoembryonic antigen., Analytica Chimica Acta, 666, 1-2, 91-96.

Yeh, J.I.; Du, S.; Xia, T.; Lazareck, A.; Kim, J-H.; Xu, J.; and Nel, A.E. (2007). Coordinated Nanobiosensors for Enhanced Detection: Integration of Three-Dimensional Structures to Toxicological Applications. ECS Transactions 3(29), 115-126.

Yeh, J.I.; Shivachev, B.; Rapireddy, S.; Gil, R.R.; Du, S.; Ly, D. (2010). Crystal Structure of Chiral $\gamma$ PNA with Complementary DNA Strand: Insights into the Stability and Specificity of Recognition and Conformational Preorganization. J. Am. Chem. Soc. 132 (31), 10717-10727. 
Yin, X.B.; Qi, B.; Sun, X.; Yang, X.; Wang, E. (2005). 4-(Dimethylamino)butyric acid labeling for electrochemiluminescence detection of biological substances by increasing sensitivity with gold nanoparticle amplification. Anal. Chem. 77, 3525-3530.

Yin, Z.; Liu, Y.; Jiang, L.P.; Zhu, J.J. (2011). Electrochemical immunosensor of tumor necrosis factor a based on alkaline phosphatase functionalized nanospheres. Biosensors and Bioelectronics, 26, 5, 1890-1894.

Yoo, S.; Kim, D.; Park, T.; Kim, E.; Tamiya, E.; Lee, S. (2010). Detection of the most common corneal dystrophies caused by BIGH3 gene points mutations using multispot goldcapped nanoparticle array chip, Anal. Chem. 82, 1349-1357.

Young, K.L.; Xu, C.J.; Xie, J.; Sun, S.H. (2009). Conjugating Methotrexate to magnetite $\left(\mathrm{Fe}_{3} \mathrm{O}_{4}\right)$ nanoparticles via trichloro-s-triazine. J. Mater. Chem. 19, 6400.

Yu, H.; Sheng, Q.L.; Li, L.; Zheng, J.B. (2007) Rapid electrochemical preparation of a compact and thick Prussian blue film on composite ceramic carbon electrode from single ferricyanide solution in the presence of HAuCl4, J. Electroanal. Chem., 606, 55-62.

Yu, X.; Kim, S.N.; Papadimitrakopoulos, F.; Rusling, J.F. (2005).Protein immunosensor using single-wall carbon nanotube forests with electrochemical detection of enzyme labels. Mol. Biosyst. 1, 70-75.

Yu, X.; Munge, B.; Patel, V.; Jensen, G.; Bhirde, A.; Gong, J.; Kim, S.; Gillespie, J.; Gutkind, S.; Papadimitrakopolous, F.; Rusling, J.F. (2006). Carbon nanotube amplification strategies for highly sensitive immunosensing of cancer biomarkers in serum and tissue. J. Am. Chem. Soc. 128, 11199-11205.

Yuan, Y.R.; Yuan, R.; Chai, Y.Q.; Zhuo, Y.; Shi, Y.T.; He, X.L.; Miao, X.M. (2007). A reagentless amperometric immunosensor for alpha-fetoprotein based on gold nanoparticles/TiO2 colloids/prussian blue modified platinum electrode. Electroanalysis 19, 1402-1410.

Zakharchuk, N.F.; Meyer, B.; Hennig, H.; Scholz, F.; Jaworski, A.; Stojek, Z. (1995). A comparative study with Prussian-Blue-modified graphite paste electrodes and solid graphite electrodes with mechanically immobilized Prussian Blue, J. Electroanal. Chem. 398, 23-35.

Zhai, Y.; Yu, J.; Iruela-Arispe, L.; Huang, W.Q.; Wang, Z.; Hayes, A.J.; Lu, J.; Jiang, G.; Rojas, L; Lippman, M.E. (1999). Inhibition of angiogenesis and breast cancer xenograft tumor growth by vegi, a novel cytokine of the tnf superfamily. Int. J. Cancer 82, 131-136.

Zhang, G.P.; Wang, X.N.; Yang, J.F.; Yang, Y.Y.; Xing, G.X.; Li, Q.M.; Zhao, D.; Chai, S.J.; Guo., J.Q. (2006) Development of an immunochromatographic lateral flow test strip for detection of $\beta$-adrenergic agonist Clenbuterol residues., Journal of Immunological Methods, 312, 1-2, 27-33.

Zhang, L.Y.; Yuan, R.; Chai, Y.Q.; Li, X.L.; Zhong, X.; Zhu, Q. (2005). An amperometric immunosensor for rubella vaccine. Anal. Lett. 38, 1549-1558.

Zhang, N.; Wilkop, T.; Lee S. and Cheng, Q. (2007). Bi-functionalization of a patterned Prussian blue array for amperometric measurement of glucose via two integrated detection schemes, Analyst 132, 164-172. 
Zhang, S.; Du P.; Li F. (2007). Detection of prostate specific antigen with 3,4-diaminobenzoic acid (DBA) $-\mathrm{H}_{2} \mathrm{O}_{2}-\mathrm{HRP}$ voltammetric enzyme-linked immunoassay system. Talanta, 72, 4, 1487-1493.

Zhang, S.; Zheng, F.; Wu, Z.; Shen, G.; Yu, R. (2008). Highly sensitive electrochemical detection of immunospecies based on combination of Fc label and PPD film/gold nanoparticle amplification., Biosensors and Bioelectronics, 24, 1, 129-135.

Zhang, X.; Wu, Y.; Tu, Y.; Liu, S. (2008). A reusable electrochemical immunosensor for carcinoembryonic antigen via molecular recognition of glycoprotein antibody by phenylboronic acid self-assembly layer on gold. Analyst 133, 485-492.

Zhao, H.T.; Ju, H.X. (2006) Multilayer membranes for glucose biosensing via layer- by-layer assembly of multiwall carbon nanotubes, Anal. Biochem., 350, 138-144.

Zheng, M.; Huang, X. (2004) Nanoparticles comprising a mixed monolayer for specific bindings with biomolecules, J. Am. Chem. Soc. 126, 12047-12054

Yin Z.; Liu, Y.; Jiang, L.P.; Zhu, J.J. (2011). Electrochemical immunosensor of tumor necrosis factor a based on alkaline phosphatase functionalized nanospheres., Biosensors and Bioelectronics, 26, 5, 1890-1894.

Song, Z.; Yuan, R.; Chai, Y.; Yin, B.; Fu, P.; Wang, J. (2010). Multilayer structured amperometric immunosensor based on gold nanoparticles and Prussian blue nanoparticles/nanocomposite functionalized interface., Electrochimica Acta, 55, 5, 1778-1784.

Liu, Z.; Yuan, R.; Chai, Y.; Zhuo, Y.; Hong, C.; Yang, X. (2008). Highly sensitive, reagentless amperometric immunosensor based on a novel redox-active organic-inorganic composite film., Sensors and Actuators B: Chemical, 134, 2, 625-631.

Zhu, H.; White, I.M.; Suter, J.D.; Zourob, M.; Fan, X. (2008). Opto-fluidic micro-ring resonator for sensitive label-free viral detection, Analyst, 133, 356-360.

Liu, Z.; Robinson, J.T.; Sun, X. and Dai, H. (2008). PEGylated Nanographene Oxide for Delivery of Water-Insoluble Cancer Drugs., J. Am. Chem. Soc. 130, 10876-10877.

Zhuo, Y., Yuan, R., Chai, Y.Q., Tang, D.P., Zhang, Y., Wang, N., Li, X.L., Zhu, Q., 2005. A reagentless amperometric immunosensor based on gold nanoparticles/thionine/Nafion-membranemodified gold electrode for determination of _-1-fetoprotein. Electrochem. Commun. 7, 355-360.

Zhuo, Y.; Yuan, R.; Chai, Y.Q.; Tang, D.P.; Zhang, Y.; Wang, N.; Li, X.L.; Zhu, Q. (2005). A reagentless amperometric immunosensor based on gold nanoparticles/thionine/Nafion-membranemodified gold electrode for determination of _-1-fetoprotein. Electrochem. Commun. 7, 355-360.

Zinkin, N.T.; Grall, F.; Bhaskar, K.; Otu, H.H.; Spentzos, D.; Kalmowitz, B.; Wells, M.; Guerrero, M.; Asara, J.M.; Libermann, T.A.; Afdhal, N.H. (2008) Serum proteomics and biomarkers in hepatocellular carcinoma and chronic liver disease, Clin. Cancer Res. 14, 470-477.

Zong Dai, Feng Yan, Hua Yu, Xiaoya Hu, Huangxian Ju., Novel amperometric immunosensor for rapid separation-free immunoassay of carcinoembryonic antigen., Journal of Immunological Methods, Volume 287, Issues 1-2, April 2004, Pages 13-20 


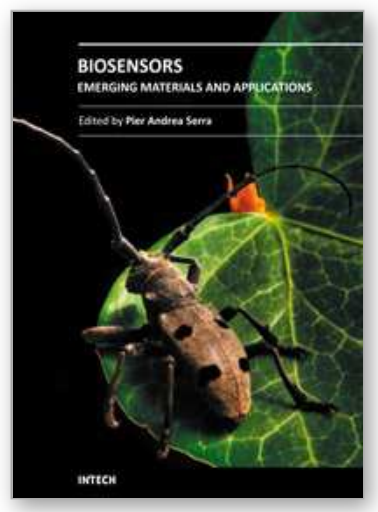

\author{
Biosensors - Emerging Materials and Applications \\ Edited by Prof. Pier Andrea Serra
}

ISBN 978-953-307-328-6

Hard cover, 630 pages

Publisher InTech

Published online 18, July, 2011

Published in print edition July, 2011

\begin{abstract}
A biosensor is a detecting device that combines a transducer with a biologically sensitive and selective component. Biosensors can measure compounds present in the environment, chemical processes, food and human body at low cost if compared with traditional analytical techniques. This book covers a wide range of aspects and issues related to biosensor technology, bringing together researchers from 19 different countries. The book consists of 27 chapters written by 106 authors and divided in three sections: Biosensors Technology and Materials, Biosensors for Health and Biosensors for Environment and Biosecurity.
\end{abstract}

\title{
How to reference
}

In order to correctly reference this scholarly work, feel free to copy and paste the following:

Zihni Onur Uygun and Mustafa Kemal Sezgintürk (2011). Biosensors for Cancer Biomarkers, Biosensors Emerging Materials and Applications, Prof. Pier Andrea Serra (Ed.), ISBN: 978-953-307-328-6, InTech, Available from: http://www.intechopen.com/books/biosensors-emerging-materials-and-applications/biosensorsfor-cancer-biomarkers

\section{INTECH}

open science | open minds

\section{InTech Europe}

University Campus STeP Ri

Slavka Krautzeka 83/A

51000 Rijeka, Croatia

Phone: +385 (51) 770447

Fax: +385 (51) 686166

www.intechopen.com

\section{InTech China}

Unit 405, Office Block, Hotel Equatorial Shanghai

No.65, Yan An Road (West), Shanghai, 200040, China

中国上海市延安西路 65 号上海国际贵都大饭店办公楼 405 单元

Phone: +86-21-62489820

Fax: +86-21-62489821 
(C) 2011 The Author(s). Licensee IntechOpen. This chapter is distributed under the terms of the Creative Commons Attribution-NonCommercialShareAlike-3.0 License, which permits use, distribution and reproduction for non-commercial purposes, provided the original is properly cited and derivative works building on this content are distributed under the same license. 